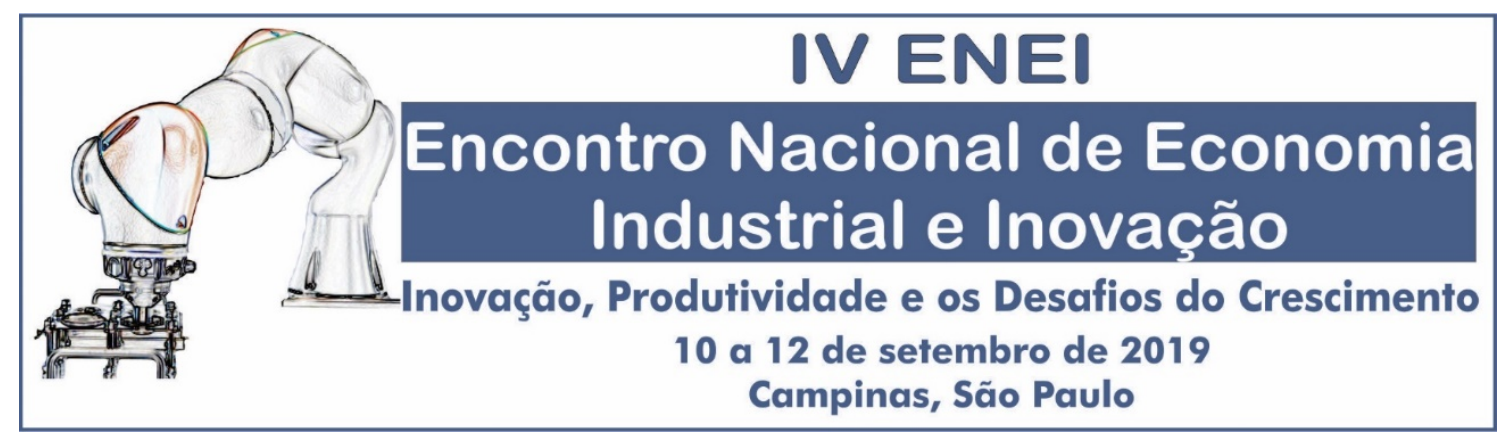

\title{
A Trajetória dos Estudantes de Pós-Graduação Stricto Sensu no Brasil: atrito e tempo para conclusão nos cursos de mestrado e doutorado
}

Daniel Gama e Colombo ${ }^{\mathrm{i}}$

\section{Resumo:}

Este artigo apresenta um primeiro esforço de investigar a taxa de atrito e tempo para conclusão nos cursos de mestrado e doutorado no país. Para isso, é apresentado um conjunto inicial de estatísticas descritivas, com base em microdados identificados dos estudantes. A taxa de atrito média nos dois níveis encontra-se em torno de $12 \%$. A maior parte dos alunos titulados no mestrado concluí o curso até o fim do terceiro, enquanto no doutorado isso ocorre até o fim do quinto ano. A proporção de alunos que abandonam ou são desligados tende a aumentar com o tempo no curso, sendo ainda observada uma taxa de atrito inferior para mulheres, alunos mais jovens e estudantes de instituições públicas. Não foram encontrados indícios de que o tempo para conclusão possa estar relacionado ao sexo, à idade dos estudantes e à natureza jurídica das instituições de ensino.

Palavras-chave: atrito; pós-graduação; tempo para conclusão; trajetória educacional.

\section{Abstract:}

This article presents a first investigation on the attrition rate and time to completion of master and doctorate courses in Brazil. Descriptive statistics of the students' trajectory is presented herein, based on students' identified microdata. An average attrition rate of around $12 \%$ is found for both masters and doctorate programs. Most master's degree students complete their program up to the end of the third year, while most doctorate students earn their degrees until the end of the fifth year. I found that the share of drop-out students increases as they progress in the program; and that women, younger students and public institutions present a lower attrition rate. On the other hand, the data do not suggest that time to completion is related to gender, student age and the legal nature of educational institutions.

Key-words: attrition; educational trajectory; graduate programs; time to completion.

Área Temática ABEIN: 5.8 - Indicadores de Ciência, Tecnologia, Inovação.

Classificação JEL: I21; I23.

\footnotetext{
${ }^{\text {i }}$ Membro da Diretoria de Estudos Educacionais do Instituto de Estudos e Pesquisas Educacionais Anísio Teixeira. Doutor em Economia do Desenvolvimento pela Faculdade de Economia, Administração e Contabilidade da Universidade de São Paulo.
} 


\section{A Trajetória dos Estudantes de Pós-Graduação Stricto Sensu no Brasil: atrito e tempo para conclusão nos cursos de mestrado e doutorado}

\section{Introdução}

Os cursos de pós-graduação stricto sensul (mestrado e doutorado) em instituições de ensino brasileiras expandiram substancialmente nas últimas décadas (CAPES, 2017b), transformando o cenário desse nível educacional no país. Essa expansão constitui um fenômeno internacional observado em diferentes países (OECD, 2016b), e permitiu que outros desafios e questões entrassem na agenda e passassem a interessar acadêmicos, legisladores e gestores públicos. Todavia, até o momento pouco se sabe acerca da trajetória dos estudantes brasileiros nos cursos de mestrado ou doutorado ${ }^{2}$, assim como sobre os fatores que determinam essa trajetória, em especial aquelas relacionadas ao tempo para titulação e ao atrito (abandono ou desligamento) $^{3}$. Este artigo apresenta um primeiro esforço nesse sentido, apresentando e discutindo um conjunto inicial de informações que fornece o quadro geral dessas questões na pós-graduação brasileira.

Tais temas são recentes também na literatura internacional, embora já tenham sido objeto de estudos em diferentes países (Bair e Haworth, 2004). Em especial, o atrito foi negligenciado por muito tempo devido à baixa visibilidade dos estudantes que não obtêm o título, não sendo tais casos interpretados como um problema da instituição (Lovitts, 2002; Ali et al., 2007). Mas as altas taxas de atrito observadas no doutorado em diferentes países - próximas de 40\% a 60\% (Bair e Haworth, 2004; Park, 2005; Ampaw e Jaeger, 2012) levaram a uma nova percepção sobre esse problema. Também colaborou para o crescimento do interesse nesse tema uma melhor compreensão das consequências negativas do encerramento malsucedido para o aluno (financeira e psicologicamente), para o seu orientador e também para a universidade (Lovitts, 2002; Greene, 2015; Wollast et al., 2018), além do desperdício de tempo e recursos com a educação interrompida (Van de Schoot et al., 2013).

Não obstante a discussão acerca da educação em nível de mestrado e doutorado no Brasil desde o I Plano Nacional de Pós-Graduação (Brasil, 1975), o debate sobre os fatores que influenciam ou determinam o atrito e o tempo para conclusão é praticamente inexistente no país. Este artigo chama atenção para importância desses tópicos e busca compreender a trajetória dos alunos da pós-graduação brasileira à luz do conhecimento desenvolvido na literatura internacional e dos dados dos alunos informados pelos programas e coletados pela Coordenação de Aperfeiçoamento de Pessoal de Nível Superior (CAPES, 2017a).

O objetivo do trabalho é traçar um panorama geral do atrito e tempo para titulação dos alunos de mestrado e doutorado no país. Para isso, é apresentado um conjunto inicial de estatísticas descritivas e informações que descreva tais indicadores, considerando também um grupo de características pessoais e institucionais dos alunos e de seus cursos e instituições de ensino. $\mathrm{O}$ artigo não se propõe a traçar uma relação de causalidade ou evidenciar os efeitos de quaisquer variáveis na trajetória dos estudantes, mas

\footnotetext{
${ }^{1}$ A pós-graduação brasileira divide-se em stricto sensu - mestrado e doutorado - e lato sensu - cursos de especialização, MBA (Master Business Administration) e outros (Resolução do Conselho Nacional de Educação / Câmara de Educação Superior $\mathrm{n}^{\circ}$ 1, de 3 de abril de 2001). Este artigo trata exclusivamente dos cursos de mestrado e doutorado, devendo a expressão "pósgraduação" ser compreendida nesse sentido.

${ }^{2}$ Conforme a definição da CAPES (2019) adotada neste artigo, um curso de pós-graduação pode ser um mestrado acadêmico, um mestrado profissional ou um doutorado específico, enquanto um ‘programa de pós-graduação' constitui um núcleo acadêmico mais amplo, que pode oferecer um ou mais cursos.

${ }^{3}$ Diferentes classificações ou denominações foram utilizadas para descrever ou se referir ao fenômeno da exclusão ou saída do estudante de um curso de mestrado ou doutorado sem a obtenção do título, como evasão (ANDIFES et al., 1996; Fernandes et al., 2017) abandono ou desligamento (CAPES, 2019) ou saída ('dropout'; Bair e Haworth, 2004).Neste estudo, optou-se por utilizar o termo 'atrito' e 'persistência', por serem recorrentes na literatura teórica e empírica citada ao longo do trabalho. Atrito é definido como a proporção dos estudantes de uma coorte de um programa específico que não completa o programa com sucesso, não obtendo a titulação (Spady, 1970; Tinto, 1975; Council of Graduate Schools, 2004; Tinto, 2006; Spronken-Smith et al., 2018). Além disso, considerando a classificação utilizada pela CAPES (2019) na coleta e tabulação da base de dados para expressar essa situação, a expressão 'abandono ou desligamento' é utilizada como sinônimo de atrito, em especial na parte empírica (seção 4).
} 
apenas levantar indícios de como diferentes fatores podem influenciar suas escolhas, sugerindo pontos a serem investigados e contribuindo assim para a construção de uma agenda de pesquisa no tema.

A segunda parte que sucede esta introdução resume os principais marcos teóricos e a literatura empírica internacional que abordou esses temas em outros países. A terceira parte descreve os principais desenvolvimentos recentes da pós-graduação no país que se encontram relacionados com as escolhas dos estudantes ao longo do curso, nos termos da literatura consultada. A quarta parte traz a análise empírica da trajetória dos estudantes brasileiros de pós-graduação, apresentando em primeiro lugar os dados gerais e por grande área de conhecimento (UNESCO, 1997), e depois classificando os estudantes de acordo com características pessoais e atributos institucionais de seus cursos e universidades. A quinta e última seção conclui o artigo, resumindo os principais pontos e apontando caminhos para futuras pesquisas.

\section{A Literatura sobre Atrito e Tempo para Titulação na Pós-Graduação}

Esta seção traz um apanhado da literatura internacional sobre atrito e tempo para conclusão na pósgraduação. Tratando-se de questões não exploradas pela comunidade acadêmica educacional brasileira, o objetivo é oferecer um panorama dos debates e do conhecimento desenvolvido nos temas, destacando as principais contribuições de estudos realizados em outros países. Embora tais resultados possam não ser imediatamente aplicáveis ao caso brasileiro (devido a diferenças culturais e institucionais), eles fornecem as bases para interpretar os dados para o país (apresentados na seção 4) e para proposição de uma agenda de pesquisa.

Essa literatura é em boa medida derivada da discussão desenvolvida para o nível de graduação a partir da década de 1970. No caso do atrito, os estudos anteriores que tratavam do assunto eram eminentemente empíricos e sem uma base teórica sólida (Spady, 1970), com foco no estudante e nos aspectos psicológicos que levam ao abandono ou desligamento, uma abordagem que ficou conhecida como 'culpabilização da vítima' (Tinto, 2006). Modelos foram então desenvolvidos para se contrapor a essa perspectiva, destacando o papel da sociedade, do ambiente, das instituições e dos retornos da educação superior nas decisões tomadas pelos estudantes e nos esforços que esses empreendem para concluir seus estudos.

\subsection{Os principais arcabouços teóricos}

Duas linhas teóricas foram desenvolvidas para tentar explicar os fatores e as decisões que determinam a persistência e tempo de duração na pós-graduação (Geven et al., 2018): a abordagem da integração, que destaca a interação entre o estudante e o ambiente escolar como fator crucial para determinar o sucesso e o atrito (Tinto, 1975); e os modelos econômicos da teoria do capital humano, que encaram a tomada de decisão do estudante como uma análise de custos e benefícios, considerando as estruturas sociais e expectativas de sucesso e retorno (Beekhoven et al., 2002).

Os teóricos da integração basearam-se no modelo de suicídio de Durkheim (2000) para explicar o abandono de um curso de nível superior (Spady, 1970; Tinto, 1975). A universidade é entendida como um sistema social dotado de valores e estruturas, e, nesse sentido, a decisão de se retirar desse sistema pode ser compreendida como análoga ao suicídio. O ponto central desses modelos é a ênfase no baixo nível de integração do estudante com a comunidade como principal elemento explicativo do atrito (Tinto, 1975). Essa abordagem não dá maior importância ao tempo que o estudante leva para concluir o curso, sendo esse um tema pouco explorado por esses autores.

A integração estudante-universidade compreende diferentes dimensões, sendo apresentados principalmente dois conjuntos de fatores nos modelos clássicos (Spady, 1970; Tinto, 1975): em primeiro lugar, o sistema acadêmico ou de resultados, compreendido como o plexo de recompensas, notas e avaliações obtidas pelo estudante, e também o seu comprometimento com a conclusão de seu curso ( 'goal commitment'); e o sistema social, caracterizado pelas relações desenvolvidas com outros participantes e pelo compromisso com a instituição de ensino ('institutional commitment'). Nos termos dessa teoria, quanto maior a integração de um estudante com a universidade em cada uma dessas dimensões, menor será a probabilidade de que ele abandone ou seja desligado do curso. 
Essa integração, entretanto, não se observa ou constitui apenas uma vez, sendo um processo contínuo e longitudinal de interações durante o curso. Essa natureza longitudinal é usualmente representada através de gráficos que identificam atributos, fatores e decisões que afetam a integração em cada uma das etapas. $\mathrm{O}$ estudante ingressa na pós-graduação munido de um conjunto de atributos prévios (individuais, familiares e currículo acadêmico), sendo exposto a diferentes demandas e influências ao longo do tempo, que definirão e modificarão o seu nível de integração com esse ambiente a cada período (Spady, 1970), especialmente no primeiro ano, considerado uma fase crítica nesses modelos (Tinto, 2006).

Essa abordagem foi inicialmente desenvolvida para os estudantes tradicionais dos cursos de graduação, e por isso tinha alcance limitado quando considerados outros grupos estudantis e arcabouços institucionais (Davidson e Wilson, 2013). Por esse motivo, esse constructo teórico teve que ser posteriormente adaptado para que pudesse explicar também o atrito na pós-graduação (Girves e Wemmerus, 1988), em especial para destacar a maior importância da dimensão acadêmica nesses casos (Lovitts, 2002).

$\mathrm{Na}$ adaptação de seu próprio modelo para o doutorado, Tinto (1993) sugeriu que esses alunos passam por três fases distintas, nas quais a integração e a decisão de abandono são definidas por diferentes fatores: (a) a transição inicial ou entrada, moldada primordialmente pelos atributos individuais, compromissos externos (principalmente relacionados ao trabalho e família), financiamento e experiência institucional; (b) a etapa de desenvolvimento (conclusão das disciplinas e aprovação da 'candidatura' ou qualificação do projeto de pesquisa), influenciada pelas relações desenvolvidas com os professores e outros acadêmicos da instituição; e (c) a fase final de pesquisa, novamente marcada pelos compromissos externos e financiamento (Tinto, 1993).

Já os modelos econômicos da teoria do capital humano, por outro lado, partem da interpretação da educação como investimento. Indivíduos tomam suas decisões de iniciar e continuar um curso de maneira racional, comparando o retorno e os custos envolvidos e analisando outras alternativas de investimento disponíveis, optando pela escolha que maximiza sua renda ou utilidade (Becker, 1994; Paulsen, 2001; Becker, 2009). Nessa análise, são levados em consideração elementos financeiros ou não (Beekhoven et al., 2002), como o valor de mensalidades e demais custos escolares, o tempo e esforço dedicados ao estudo, o prêmio salarial esperado com o título, a satisfação pessoal com o conhecimento e habilidades adquiridas, as estruturas sociais e as expectativas pessoais de sucesso ou reprovação no curso.

Uma dificuldade dos modelos de escolha racional para explicar o atrito é a existência de escolhas prévias dos estudantes. Um aluno de pós-graduação já analisou anteriormente os fatores citados e concluiu que aquele curso constituía o investimento ótimo ou mais vantajoso, optando por se matricular e tentar obter o título. Assim, abandonar ou alterar o tempo inicialmente estimado para o curso representa uma alteração dessa escolha inicial, que só pode ocorrer caso aconteça uma mudança nos custos e benefícios estimados inicialmente, ou caso o estudante obtenha informações adicionais para rever sua posição original (Ampaw e Jaeger, 2012). Dessa maneira, para explicar as decisões após o ingresso, os modelos de capital humano precisam incorporar noções de incerteza e informação incompleta, além de ser estruturados a partir de uma perspectiva dinâmica, compostos de diferentes períodos nos quais os alunos possam obter novos inputs e informações para chegar a uma nova conclusão (Breneman, 1976; Ehrenberg e Mavros, 1992; Breen e Goldthorpe, 1997; Beekhoven et al., 2002).

O modelo de Breneman (1976) ganhou destaque como uma das primeiras formulações que tentam explicar essas decisões para o caso do doutorado. A formação de um doutor é compreendida como um 'processo produtivo', no qual os interesses de dois grupos - estudantes e professores - interagem em direções convergentes ou opostas. De um lado, estudantes suportam a maior parte do custo, e por esse motivo buscariam concluir o doutorado o mais breve possível. Entretanto, eles podem desacelerar seu progresso a fim de melhorar suas notas e aprimorar o currículo, para elevar o retorno esperado quando ingressarem no mercado. Por outro lado, professores e departamentos utilizam a força de trabalho de seus doutorandos de diferentes formas, com impacto no tempo e probabilidade de conclusão: programas que dependem desses alunos para lecionar disciplinas introdutórias de graduação tenderiam a estruturar trajetórias mais longas, trazendo maior incerteza e elevando a taxa de atrito; por outro lado, áreas com maior ênfase na pesquisa laboratorial precisam que seus alunos produzam resultados rapidamente para financiar os custos da infraestrutura, levando a cursos mais curtos e maiores índices de conclusão (Breneman, 1976). 
Outros autores seguiram esse arcabouço e apresentaram modelos que formalizam a escolha estudantil em um cenário de informação imperfeita ou incompleta. O modelo de riscos concorrentes (competing risks model) de Ehrenberg e Mavros (1992) propõe que os estudantes avaliem a sua situação a cada período, maximizando o valor presente de sua renda: eles podem decidir prosseguir no curso, abandoná-lo ou tentar antecipar a sua conclusão através de um esforço adicional. Em uma formulação similar, Breen e Goldthorpe (1997) modelaram a escolha individual de persistir ou abandonar um curso através de uma árvore decisória, na qual os estudantes avaliam o custo dos estudos, a probabilidade de sucesso e o valor ou utilidade subjetiva que eles atribuem a cada resultado, considerando principalmente o risco de rebaixamento de classe social.

Ambas as correntes teóricas descritas apresentam elementos explicativos relevantes para compreender a trajetória dos estudantes de mestrado e doutorado, não devendo ser compreendidas como contraditórias. Dar ênfase à integração não implica negar a decisão racional ou a análise de custos e benefícios, assim como a maximização da utilidade pode incorporar fatores relacionados às relações sociais ou recompensas acadêmicas. Em um estudo com estudantes holandeses, Beekhoven et al. (2002) testaram e concluíram que há evidências empíricas de que as duas abordagens ajudam a explicar o atrito e tempo de titulação, e com base nessa conclusão propuseram um modelo híbrido que considera as duas linhas de pensamento.

\subsection{A literatura empírica: fatores que influenciam o atrito e tempo para conclusão}

Seguindo esses marcos teóricos, uma crescente literatura empírica vem se desenvolvendo para avaliar e tentar explicar como diferentes variáveis afetam a probabilidade de sucesso e o tempo esperado para titulação em um curso de pós-graduação. Um estudo aborda a temática no país, utilizando dados agregados para fazer estimativas acerca do abandono ou desligamento, mas sem apresentar qualquer desagregação ou investigar as características pessoais dos alunos ou atributos das instituições em que eles estudavam. (Fernandes et al., 2017). Por esse motivo, recorre-se à literatura empírica internacional para identificar os fatores mais relevantes para discutir esses temas, ressalvando-se novamente que as conclusões desses trabalhos não são necessariamente aplicáveis ao caso brasileiro, devido a características próprias desse nível educacional em cada país.

A maior parte desses estudos analisou cursos nos Estados Unidos (Abedi e Benkin, 1987; Espenshade e Rodriguez, 1997; Ampaw e Jaeger, 2012; Cohen, 2012; Zhou e Okahana, 2019), embora também haja pesquisas sobre estudantes em outros países, como o Reino Unido, Holanda, Bélgica, Canadá e Nova Zelândia (Sheridan e Pyke, 1994; Booth e Satchell, 1995; Beekhoven et al., 2002; Van de Schoot et al., 2013; Kyvik e Olsen, 2014; Matute, 2014; Spronken-Smith et al., 2018; Wollast et al., 2018). A quase totalidade das análises considerou apenas os cursos de doutorado ${ }^{4}$. Outra limitação apontada é que muitos estudos investigam um número reduzido de instituições ou programas (Bair e Haworth, 2004), havendo poucas pesquisas que consideram uma amostra mais abrangente de alunos (Groenvynck et al., 2013; Matute, 2014).

Os vários fatores que afetam o tempo e persistência nos cursos de pós-graduação podem ser divididos em três grupos (Van de Schoot et al., 2013): fatores institucionais, que incluem atributos da instituição de ensino e da infraestrutura de pesquisa; características pessoais e socioeconômicas do aluno, tais como o gênero, idade, estado civil e expectativas pessoais; e a supervisão ou suporte acadêmico, que abarca a qualidade do orientador e o apoio de outros colegas ou professores. O financiamento (ou suporte financeiro) e a área de conhecimento destacam-se como os fatores mais estudados e considerados importantes preditores da trajetória estudantil (Wollast et al., 2018).

Há um consenso entre os autores de que o financiamento eleva a probabilidade de sucesso e reduz o tempo para titulação, e estudos em diferentes países apresentaram evidências e chegaram a essa conclusão (Abedi e Benkin, 1987; Sheridan e Pyke, 1994; Bair e Haworth, 2004; Gururaj et al., 2010; Mendoza et al., 2014; Van Der Haert et al., 2014; Spronken-Smith et al., 2018). Estudantes que recebem financiamento podem dedicar seus esforços e tempo para tarefas acadêmicas, além de não terem a responsabilidade e

\footnotetext{
${ }^{4}$ Não se sabe ao certo o motivo pelo qual os cursos de mestrado foram negligenciados por essa literatura. Algumas possíveis explicações sugeridas para essa lacuna na literatura são o curto tempo para titulação, a menor exigência e dedicação exigidas dos discentes e a menor complexidade da dissertação final (Cohen, 2012).
} 
preocupação de obter recursos e sustento por meio de outras atividades profissionais (Herzig, 2004; Mendoza et al., 2014). Além disso, a maior dedicação viabilizada pelo financiamento eleva o nível de integração do estudante ao ambiente acadêmico, reduzindo a probabilidade de atrito (Mwenda, 2010).

$\mathrm{O}$ efeito do financiamento, contudo, pode variar dependendo do tipo de benefício financeiro e da área de conhecimento: bolsas vinculadas a projetos científicos ('research assistantships') trariam um resultado maior em áreas em que a pesquisa é mais desenvolvida de maneira coletiva, como as áreas STEM (ciência, tecnologia, engenharia e matemática), enquanto bolsas individuais sem contrapartida ('fellowships') seriam mais eficazes quando a pesquisa é feita individual e isoladamente, como no caso das humanidades (Mendoza et al., 2014).

A maior parte das análises também concorda que as diferentes áreas do conhecimento apresentam taxas de atrito e tempos de titulação esperados distintos (Espenshade e Rodriguez, 1997; Bair e Haworth, 2004; Groenvynck et al., 2013). De maneira geral, há uma ideia disseminada de que estudantes de ciências humanas possuem menor probabilidade de sucesso e levam mais tempo para completar seus estudos do que aqueles que cursam ciências exatas e naturais (Bair e Haworth, 2004; Van Der Haert et al., 2014), sendo essa impressão confirmada por estudos empíricos em diferentes países (Abedi e Benkin, 1987; Zwick, 1991; Booth e Satchell, 1995; Groenvynck et al., 2013; Matute, 2014; Wollast et al., 2018). As explicações levantadas para essa discrepância entre áreas são a disponibilidade de financiamento, a cultura acadêmica, a clareza quanto aos procedimentos e expectativas de pesquisa, o custo da infraestrutura e o envolvimento de estudantes em grupos de pesquisa (Bair e Haworth, 2004; Visser et al., 2007).

$\mathrm{O}$ efeito de características pessoais nas trajetórias estudantis na pós-graduação é objeto de controvérsia nessa literatura. Estudos nos Estados Unidos (Abedi e Benkin, 1987; Zwick, 1991) e na Bélgica (Visser et al., 2007; Groenvynck et al., 2013) concluíram que homens possuem uma taxa de abandono ou desligamento um pouco menor do que mulheres, mas esse resultado não é unânime e foi contestado por outras análises que não identificaram diferenças significantes entre os grupos após controlarem por outras variáveis, como o número de filhos (Attiyeh, 1999; Siegfried e Stock, 2001; Mastekaasa, 2006). Estudos que analisaram a raça e a idade dos alunos não identificaram diferenças substanciais no tempo ou taxa de conclusão dos estudantes causadas por essas variáveis (Attiyeh, 1999; Siegfried e Stock, 2001; Spronken-Smith et al., 2018), embora esses resultados também não sejam consensuais. Por outro lado, diversos artigos que abordaram a nacionalidade dos estudantes concluíram e apresentaram evidências na Europa e nos Estados Unidos de que estrangeiros possuem uma probabilidade de sucesso maior do que nacionais (Zwick, 1991; Espenshade e Rodriguez, 1997; Park, 2005).

Outras variáveis testadas e discutidas na literatura internacional como possíveis preditores da taxa de atrito e tempo da conclusão na pós-graduação são: as habilidades ou desempenho acadêmico prévio (Booth e Satchell, 1995; Attiyeh, 1999; Wollast et al., 2018), a dedicação aos estudos - integral ou parcial (Girves e Wemmerus, 1988; Sheridan e Pyke, 1994), a permanência na mesma universidade e área de conhecimento em que o aluno estudou anteriormente (Park, 2005; Wollast et al., 2018) e a qualidade ou desempenho científico do orientador (Girves e Wemmerus, 1988; Van Ours e Ridder, 2003).

Conforme destacado, a literatura acerca desses temas no Brasil é praticamente inexistente, não havendo um estudo que tenha investigado o efeito de características pessoais e institucionais nos estudantes brasileiros de mestrado e doutorado. A análise empírica apresentada na seção 4 representa uma primeira tentativa de lançar luz sobre essas questões. A fim de contextualizar essa investigação, a próxima parte traz um panorama geral da evolução recente da pós-graduação no país.

\section{Evolução recente da pós-graduação brasileira}

O desenvolvimento da educação em nível de pós-graduação no Brasil é recente, tendo ocorrido principalmente a partir da década de 1970 (Brasil, 1975). As últimas duas décadas representaram um período de grande expansão e evolução do quadro institucional, que acabaram por alterar o cenário dos cursos de mestrado e doutorado no país. Esta seção descreve algumas das principais evoluções e alterações que se encontram relacionadas ou que podem afetar os incentivos dos estudantes para definição de sua trajetória, conforme os argumentos e evidências apresentados pela literatura internacional. 
O primeiro ponto a ser destacado é a expansão do número de estudantes. O total de alunos de mestrado titulados por instituições brasileiras cresceu cerca de seis vezes entre 1996 e 2016, atingindo aproximadamente 60 mil no último ano desse período. A expansão do doutorado ocorreu a uma taxa similar: o total de titulados em 2016 é cerca de 6,5 vezes maior do que o número de 1996, chegando a aproximadamente 20,5 mil novos doutores a cada ano (CAPES, 2017a) ${ }^{5}$. Essa tendência de crescimento não é uma exclusividade brasileira, constituindo um fenômeno internacional observado e estudado em diferentes países (Walker et al., 2012; Nerad e Evans, 2014; OECD, 2016a).

Essa ampliação alterou o perfil do alunado de pós-graduação, com impacto em características que potencialmente interferem na taxa de persistência e tempo estimado para conclusão dos cursos. No mencionado período de duas décadas (1996-2016), as mulheres tornaram-se a maioria dos estudantes titulados, passando de $48,5 \%$ para $55 \%$ dos novos mestres e doutores. A expansão também privilegiou o ingresso de estudantes mais jovens: a proporção de alunos que ingressaram no mestrado com até 30 anos cresceu de cerca de $40 \%$ para $60 \%$ no período mencionado; e, no caso do doutorado, o percentual dos alunos com até 35 anos no ingresso aumentou de aproximadamente $40 \%$ para $70 \%$ (CAPES, 2017a). Uma pesquisa mais detalhada pode desvendar outras características dos alunos que se alteraram ao longo desse período, bem como esclarecer seus efeitos nas trajetórias e escolhas ao longo do curso.

Além disso, a expansão das áreas de conhecimento não ocorreu de maneira uniforme. Os programas 'Multidisciplinares' e de 'Ciências sociais Aplicadas' apresentaram crescimento mais acentuado no período 1996-2016, enquanto o percentual de alunos titulados nas grandes áreas de 'Engenharia, Produção e Construção' e 'Ciências Exatas e da Terra' foi reduzido ${ }^{6}$. Essa redistribuição do corpo discente pode ter reflexos nas estatísticas das trajetórias dos estudantes, uma vez que há evidências de que alunos de diferentes áreas do conhecimento possuem incentivos distintos para concluir seus cursos, levando a tempos e taxas de atrito diferenciadas (Espenshade e Rodriguez, 1997; Bair e Haworth, 2004; Groenvynck et al., 2013).

Um terceiro aspecto relevante é a evolução do arcabouço institucional que rege os cursos de mestrado e doutorado. As normas acerca desse nível educacional foram alteradas e atualizadas ao longo das últimas décadas, especialmente pela CAPES, o órgão responsável pela maior parte da regulação do ensino de pós-graduação no país. As novas normas alteraram a apresentação de propostas e o credenciamento de novos cursos $^{7}$, o funcionamento regular dos programas $^{8}$ e o processo de avaliação ${ }^{9}$, entre outros temas.

O prazo de financiamento estabelecido pelos órgãos de fomento é um ponto crucial. Atualmente, o país conta com duas principais agências federais que concedem bolsas de estudos aos alunos de pósgraduação (a CAPES e o Conselho Nacional de Desenvolvimento Científico e Tecnológico - CNPq), além das fundações de apoio e outros órgãos no nível estadual. Ambas as agências federais determinam que o prazo máximo das bolsas é de vinte e quatro meses para estudantes de mestrado, e de quarenta e oito meses para o doutorado ${ }^{10}$. A evidência empírica apresentada pela literatura internacional (Bair e Haworth, 2004; Gururaj et al., 2010) sugere que esses prazos podem ser decisivos nas decisões dos estudantes, fazendo com que eles tentem obter a titulação dentro desses limites, ou elevando a taxa de atrito após esse período.

Os cursos e programas de pós-graduação em funcionamento no país são avaliados a cada quatro anos, conforme regulamentação estabelecida pela CAPES. A avaliação é feita a partir de cinco quesitos gerais - proposta, corpo docente, corpo discente, produção intelectual e inserção social, recebendo notas de um a sete ${ }^{11}$. Entre os pontos considerados nessa avaliação encontram-se o tempo para formação de mestres

\footnotetext{
${ }^{5}$ Para uma discussão mais detalhada acerca da evolução recente dos números da pós-graduação brasileira, ver Colombo (2018).

${ }^{6} \mathrm{O}$ percentual de estudantes de mestrado titulados em programas 'Multidisciplinares' e de 'Ciências sociais Aplicadas' cresceu de $12,5 \%$ para $28 \%$ no caso do mestrado, e de $6 \%$ para 17,5\% no doutorado. No caso das 'Engenharia, Produção e Construção' e 'Ciências Exatas e da Terra', o percentual de mestres caiu de $27 \%$ para 20,5\% no mesmo período, enquanto a proporção de doutores reduziu-se de $30 \%$ para 19,5\% (CAPES, 2017a).

${ }^{7}$ Portaria CAPES 161, de 22 de agosto de 2017.

${ }^{8}$ Resolução 7 da Câmara de Educação Superior do Conselho Nacional de Educação, de 11 de dezembro de 2017.

${ }^{9}$ Portarias CAPES 182, de 14 de agosto de 2018, e 59, de 21 de março de 2017.

${ }^{10}$ Conforme a Portaria CAPES 34, de 30 de maio de 2006; e Resolução Normativa CNPq 17, de 06 de julho de 2006.

${ }^{11}$ Portaria CAPES 59, de 21 de março de 2017. Nos termos dessa legislação, são considerados regulares os programas com nota acima de quatro - se oferecerem cursos de mestrado e doutorado - ou três - se oferecerem apenas cursos de mestrado.
} 
e doutores e o percentual de alunos bolsistas efetivamente titulados ${ }^{12}$. É razoável supor que essas regras tenham impacto no desenho dos cursos, uma vez que os seus gestores possuem incentivos para estruturálos considerando esse horizonte temporal, e também para tentar reduzir os índices de abandono e desligamento, a fim de elevar a nota e prestígio dos programas.

Essas e outras transformações ocorridas ao longo das últimas décadas definiram o sistema de custos e incentivos com que os estudantes se deparam quando ingressam e ao longo da pós-graduação, afetando ainda o sistema normativo e de valores que estruturam as relações sociais e a integração dos novos alunos nas diferentes áreas. Dessa forma, o resumo apresentado nesta seção fornece um panorama geral para a leitura e discussão dos dados da trajetória dos estudantes, a ser feita a seguir.

\section{Dados sobre o Atrito e Tempo para Conclusão na Pós-Graduação Stricto Sensu no Brasil}

Nesta seção é apresentado e discutido um primeiro conjunto de dados levantados acerca do atrito e tempo para conclusão nos cursos de mestrado e doutorado em instituições de ensino brasileiras. Tratandose de uma análise inicial acerca de tópicos praticamente inexplorados na literatura nacional, este artigo não se propõe a extrair conclusões, definir ou evidenciar relações causais ou de efeito entre variáveis, ou mesmo propor recomendações de políticas públicas. O objetivo é levantar questões ou pontos importantes a serem investigados em maior detalhe, para a construção de uma agenda de pesquisa no tema, sugerindo ainda possíveis aprimoramentos ou complementações no levantamento e coleta de dados.

\subsection{Apresentação dos dados e definição da amostra}

A principal novidade deste trabalho é o estudo da trajetória dos alunos a partir dos microdados identificados confidenciais coletados pela CAPES (2017a). Esses dados foram reunidos e informados pelos respectivos programas de pós-graduação, e submetidos à CAPES pela pró-reitoria de pesquisa e pósgraduação (ou órgão similar) das faculdades ou universidades (CAPES, 2019).

Algumas escolhas de pesquisa tiveram que ser adotadas considerando a disponibilidade e consistência dos dados, a fim de garantir a viabilidade e confiabilidade da análise. Tais escolhas foram feitas considerando principalmente o ano de ingresso, o ano ou período em que o estudante se encontra, e a sua situação no curso. O ano de ingresso é identificado como a primeira vez em que um indivíduo aparece na base de dados como estudante regular de um curso específico (de mestrado ou doutorado) de uma instituição de ensino, sendo que qualquer alteração em um desses critérios é identificada como um novo ingresso.

Além disso, o período em que o aluno se encontra no curso é contado exclusivamente pelo critério cronológico, ou seja, considerando o número de anos corridos a partir do ingresso, independente das atividades ou disciplinas que o aluno tenha efetivamente realizado. Caso o estudante deixe de constar na base por um ou mais anos, a contagem do ano em que ele se encontra é interrompida, sendo reiniciada a partir do período em que ele aparece novamente como aluno.

A trajetória dos estudantes é analisada a partir da informação acerca da situação do discente no curso a cada ano, conforme informado pela instituição de ensino e constante na base de dados (CAPES, 2017a). De acordo com a classificação utilizada, o aluno pode se encontrar em uma das seguintes situações: matriculado regularmente; titulado; (situação de) abandono; ou desligamento (CAPES, 2019) ${ }^{13}$. Os metadados não apresentam uma distinção clara entre os casos de 'abandono e desligamento' (CAPES, 2019), razão pela qual se optou por tratar essas situações conjuntamente sob uma única rubrica. As taxas

\footnotetext{
${ }^{12}$ As 49 áreas de conhecimento reconhecidas pela CAPES (2017c) detalham os critérios a serem considerados na avaliação em 'Documentos de Área', considerando os quesitos e regras gerais estabelecidos pela agência. Para estabelecer os prazos de titulação a serem considerados na avaliação, algumas áreas fazem referência ou adotam os prazos das bolsas da CAPES e CNPq como parâmetros, como na 'Matemática, Probabilidade e Estatística' (Casado et al., 2016), 'Engenharia I' (Pires et al., 2016) e 'Odontologia' (Soares et al., 2016). Em outros casos, os responsáveis pelas áreas estabeleceram tempos distintos, como na 'Filosofia' - 30 meses para mestrado e 60 meses para doutorado (Figueiredo et al., 2016), 'Letras' e 'Ensino' - em ambos os casos, 30 meses para mestrado e 54 meses para doutorado (Araújo-Jorge et al., 2016; Hora et al., 2016).

${ }^{13}$ A base de dados original contempla ainda a categoria 'mudança de nível sem defesa', que se refere aos alunos de mestrado que são transferidos para o doutorado antes da conclusão do curso e obtenção do título de mestre. Esses casos são raros na amostra (em torno de $0,1 \%$ ), razão pela qual são desconsiderados na análise.
} 
ou percentuais de atrito apresentadas ao longo desta seção consideram a proporção de casos de 'abandono ou desligamento' sobre o total de alunos matriculados, seja ao longo de todo o curso ou a cada ano (Council of Graduate Schools, 2004).

A amostra foi definida inicialmente a partir do ano de ingresso dos alunos: no caso do mestrado, foram considerados apenas os alunos que ingressaram nos cursos entre os anos de 2007 e 2012, e, no caso do doutorado, os ingressantes no período 2007-2010. O marco inicial foi escolhido tendo em vista algumas inconsistências observadas nos dados de anos anteriores ${ }^{14}$, enquanto o limite final foi determinado pela disponibilidade de dados na base, considerando o tempo necessário para que os estudantes concluíssem sua trajetória ${ }^{15}$.

Além disso, seguindo o modelo de Ehrenberg e Mavros (1992), assumiu-se que há um tempo mínimo para a conclusão de um curso de pós-graduação, sendo excluídos da amostra aqueles que obtiveram sua titulação antes desse prazo. O principal argumento para essa exclusão é que tais casos parecem não tratar de alunos regulares de mestrado ou doutorado (sendo explicados, por exemplo, por passagens prévias na pós-graduação, com aproveitamento de disciplinas e atividades). O 'Relatório Sucupira' (Sucupira, 1965) - documento que estabeleceu os fundamentos da pós-graduação stricto sensu brasileira, afirmava que o prazo mínimo para conclusão deve ser de um ano para o mestrado, e de dois para o doutorado. Dessa forma, optou-se por não incluir no estudo os alunos de mestrado titulados durante o primeiro ano após o ingresso, e, no caso do doutorado, aqueles titulados nos dois primeiros anos ${ }^{16}$.

Uma última escolha para definição da amostra refere-se aos casos em que a informação acerca da saída do estudante do curso é omissa. Em diversos casos, estudantes que se encontravam regularmente matriculados em um período deixam de constar na base de dados no ano seguinte, não havendo informação para determinar se houve titulação, abandono ou desligamento, ou apenas uma suspensão temporária de atividades ${ }^{17}$. Esses casos foram excluídos da amostra, sendo considerados apenas os estudantes para os quais há informação expressa acerca do encerramento do curso, através da titulação, abandono ou desligamento.

Embora essa escolha certamente subestime o número de casos de atrito no mestrado e doutorado ${ }^{18}$, por outro lado garante-se que as análises sejam de fato baseadas em casos abandono ou desligamento. Nesse sentido, as estatísticas descritivas desta seção devem ser interpretadas como uma base mínima (ainda que subestimada) do atrito na pós-graduação brasileira. Para se ter uma ideia da magnitude a que pode chegar essa subestimação dos dados de atrito, o Gráfico 1 compara o atrito informado (conforme a amostra utilizada para a análise) com o 'atrito potencial', que soma tais casos de abandono ou desligamento informados aos de alunos que deixaram de constar na base sem informação acerca do resultado final de sua trajetória.

\footnotetext{
${ }^{14}$ A análise preliminar indicou a ausência ou disparidade nas informações acerca da situação dos alunos nos cursos informadas pelas instituições até o ano de 2007, razão pela qual esse ano foi tomado como marco inicial para análise. Em boa medida, a fragilidade dos dados anterior a esse período pode ser atribuída a alterações no sistema e método de coleta de dados, conforme descrito em CAPES (2019).

${ }^{15}$ A base de dados disponível apresenta informações dos discentes até o ano de 2016. Além disso, a análise preliminar indicou que cerca de $98 \%$ dos alunos de mestrado concluem ou se desligam do curso até o quinto ano após o ingresso, sendo o mesmo percentual observado para alunos de doutorado até o sétimo ano do curso (CAPES, 2017a). Foram considerados esses limites para definir que a amostra dos alunos de mestrado deveria contemplar apenas aqueles que ingressaram até o ano de 2012, e, no doutorado, apenas os ingressantes até 2010 .

16 Tais casos são excepcionais na base, atingindo cerca de 5\% das observações (CAPES, 2017a).

${ }^{17}$ Pesquisadores que enfrentaram problemas similares com dados de outros países (Ampaw e Jaeger, 2012; Wollast et al., 2018) consideraram tais casos como situações de atrito, entendendo que o estudante se desligou ou abandonou o curso. No citado estudo para o caso brasileiro, a taxa de atrito foi estimada a partir do número agregado de alunos matriculados e titulados a cada ano (Fernandes et al., 2017).

${ }^{18}$ É provável que uma parcela considerável dos alunos que deixaram de ser informados pelos programas sem o dado acerca do evento que levou ao encerramento do curso seja composta por casos de atrito.
} 


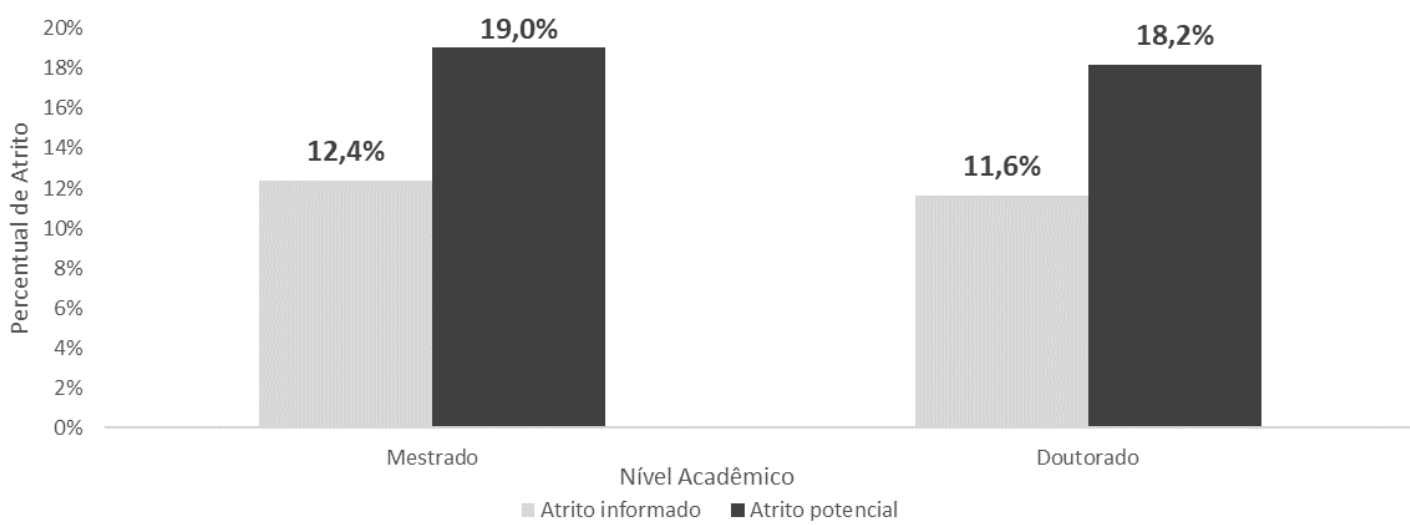

Gráfico 1. Atrito informado (alunos de mestrado e doutorado na amostra que abandonaram ou se desligaram do curso, conforme informado pela instituição de ensino; e 'atrito potencial' (alunos que abandonaram ou se desligaram do curso, conforme informado pela instituição de ensino, somados àqueles para os quais não há informação disponível acerca do resultado final de sua trajetória no curso). Fonte: elaboração própria, com base em CAPES (2017a).

A base final utilizada para análise é composta de um total de aproximadamente 367 mil estudantes de mestrado e doutorado, distribuídos por ano de ingresso conforme a Tabela 1 abaixo, que denota o crescimento da pós-graduação brasileira no período, com o aumento gradual do número de novos alunos.

Tabela 1. Número de alunos de mestrado e doutorado em instituições de ensino brasileiras na amostra, por ano de ingresso.

\begin{tabular}{|c|c|c|c|c|c|c|c|}
\hline \multirow{2}{*}{ Nível Acadêmico } & \multicolumn{7}{|c|}{ Número de Alunos na Amostra (por ano de ingresso) } \\
\hline & 2007 & 2008 & 2009 & 2010 & 2011 & 2012 & Total \\
\hline Mestrado & 43.354 & 41.787 & 47.391 & 52.547 & 57.128 & 58.998 & 301.205 \\
\hline Doutorado & 12.928 & 13.947 & 16.153 & 22.911 & & & 65.939 \\
\hline Total & 56.282 & 55.734 & 63.544 & 75.458 & 57.128 & 58.998 & 367.144 \\
\hline
\end{tabular}

Fonte: elaboração própria, com base em CAPES (2017a).

\subsection{Análise da amostra completa e por grande área de conhecimento}

Os Gráficos 2 e 3 apresentam um panorama geral da trajetória dos alunos que ingressaram em um curso de pós-graduação em instituições brasileiras no período analisado. Os gráficos mostram o tempo que esses estudantes permaneceram nos cursos, o percentual acumulado daqueles que concluíram seus estudos com sucesso ou não, e ainda os poucos alunos que continuavam matriculados ao final do período máximo considerado. 


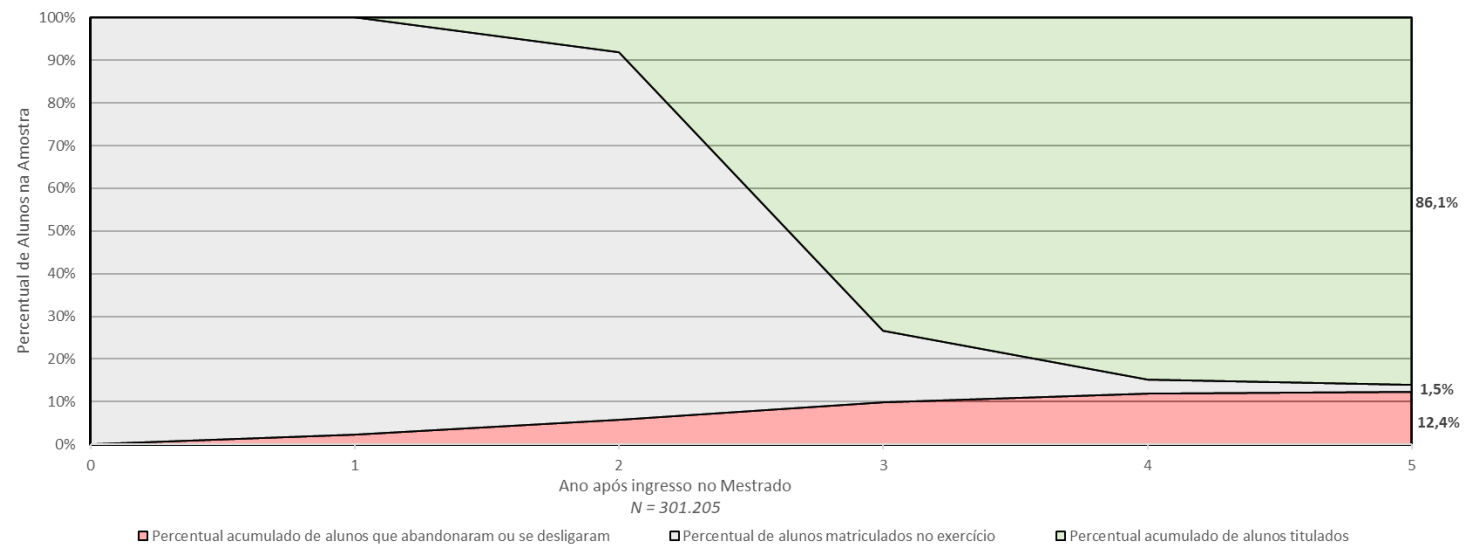

Gráfico 2. Distribuição dos alunos de mestrado na amostra por situação no curso e ano após ingresso. Fonte: elaboração própria, com base em CAPES (2017a).

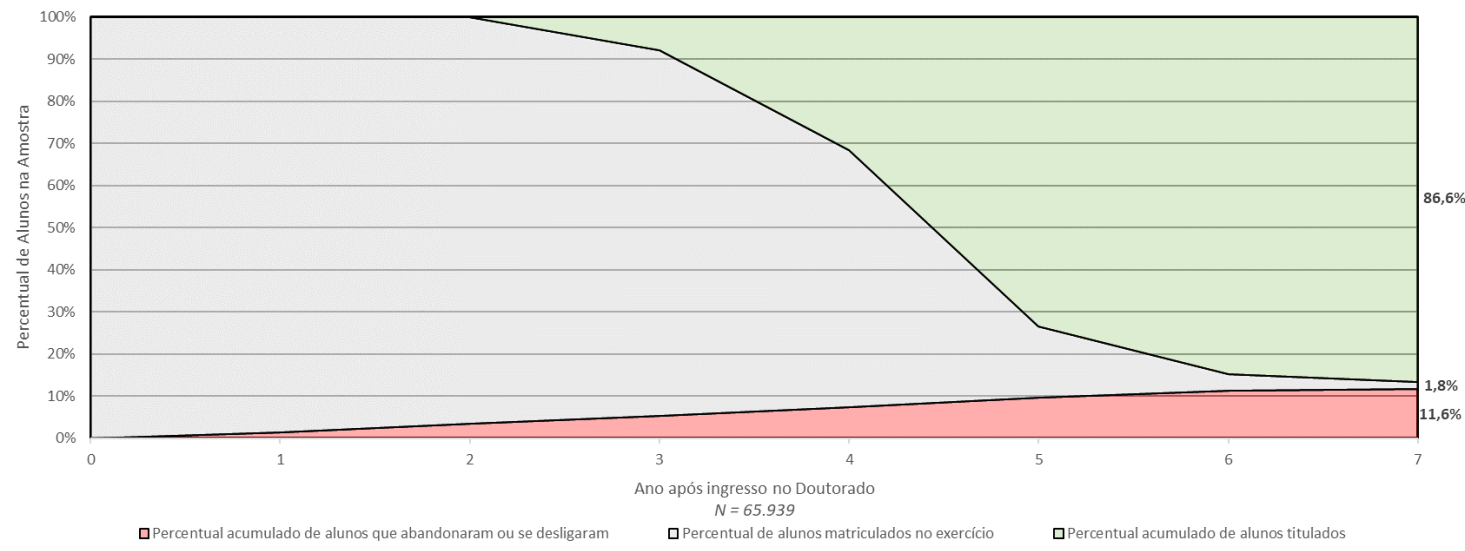

Gráfico 3. Distribuição dos alunos de doutorado na amostra por situação no curso e ano após ingresso. Fonte: elaboração própria, com base em CAPES (2017a).

Em ambos os casos, a taxa de conclusão com sucesso na amostra é alta, atingindo cerca de $86 \%$, enquanto o índice de atrito ao final do período é de aproximadamente $12 \%$, número muito inferior ao percentual de 30\% a 40\% (ou mais) reportada para os Estados Unidos, Austrália e Inglaterra (Bair e Haworth, 2004; Park, 2005; Ampaw e Jaeger, 2012). Além disso, os gráficos sugerem que o terceiro ano parece constituir um período crítico para o mestrado, no qual pouco mais de $70 \%$ dos alunos já concluíram o curso com sucesso, enquanto no doutorado esse intervalo pode ser identificado no quinto ano.

A reduzida taxa de atrito não permite distinguir com clareza os momentos em que esses casos ocorrem. Por esse motivo, os Gráficos 4 e 5 detalham essas informações: o Gráfico 4 indica a proporção de alunos matriculados no início de cada ano que optaram por abandonar ou foram desligados de seus cursos; enquanto o Gráfico 5 considera apenas a amostra de casos de abandono ou desligamento, mostrando a proporção de cada ano como período da ocorrência dos casos de atrito. 


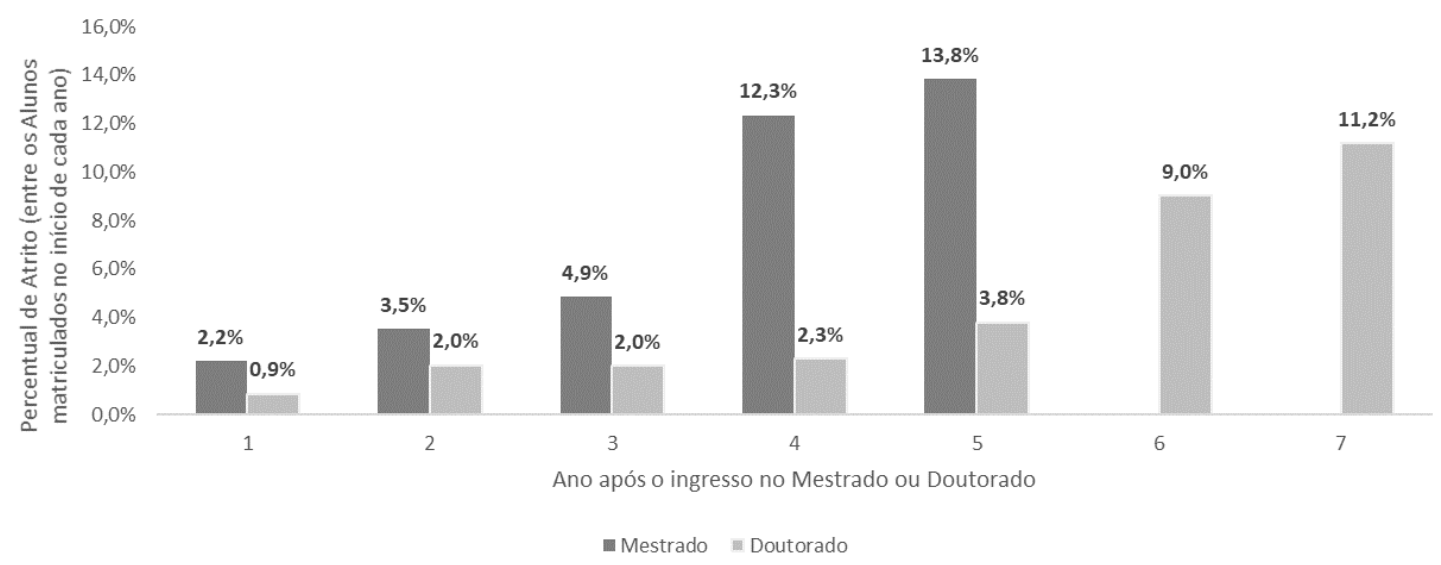

Gráfico 4. Taxa de atrito entre os alunos (na amostra) matriculados no início de cada ano após o ingresso. Fonte: elaboração própria, com base em CAPES (2017a).

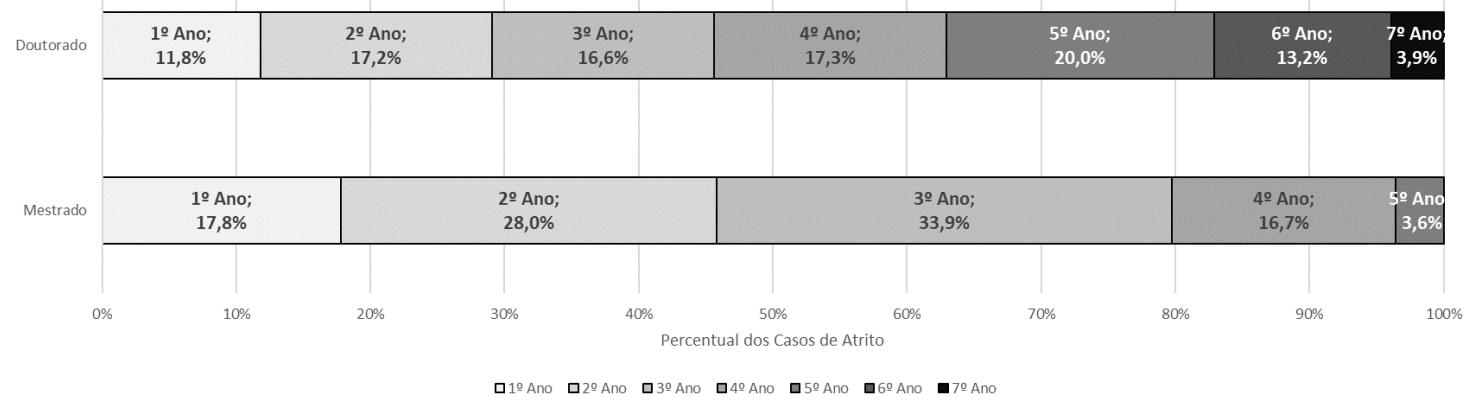

Gráfico 5. Percentual de cada ano após ingresso como período da ocorrência dos casos de atrito. Fonte: elaboração própria, com base em CAPES (2017a).

Os gráficos denotam que a taxa de atrito cresce com o tempo no curso, sugerindo que a cada ano adicional a proporção de estudantes que se desligam ou abandonam aumenta, de acordo a conclusão apresentada por Bair e Haworth (2004) em sua meta-análise no tema. Em especial, no caso do mestrado, ocorre um crescimento substancial da taxa de atrito no quarto ano (de 5\% para 12\%, aproximadamente), enquanto no caso do doutorado esse crescimento se observa especialmente no sexto período (de 4\% para $9 \%$ ). Explicar a elevação súbita do atrito nesses momentos é um ponto para futuras pesquisas, embora uma hipótese a ser explorada é a interrupção do financiamento, uma vez que tais períodos são próximos dos prazos máximos das bolsas concedidas pelas agências de fomento federais (de dois anos no mestrado e quatro anos no doutorado).

Por outro lado, o Gráfico 5 mostra que, apesar da taxa de atrito aumentar gradualmente ao longo do tempo, a maior parte dos casos ocorre nos primeiros anos ${ }^{19}$, conforme sugerido pelos teóricos da integração (Tinto, 2006). Isso indica que a fase inicial constitui uma etapa a ser considerada com maior atenção para formulação de políticas que visem a reduzir o atrito na pós-graduação.

Conforme discutido na seção 2, a disciplina ou área de conhecimento é reconhecida como um dos principais fatores que determinam a trajetória dos alunos de pós-graduação, podendo haver diferenças substanciais entre as áreas (Espenshade e Rodriguez, 1997; Bair e Haworth, 2004; Groenvynck et al., 2013). A fim de verificar se esse argumento pode ser aplicável para o caso brasileiro, os Gráficos 6 e 7 separam os alunos conforme a classificação de grandes grupos ou áreas de conhecimento estabelecida pela UNESCO (1997). Os dados sugerem que, tanto no mestrado quanto no doutorado, observa-se uma maior taxa de abandono ou desligamento entre os estudantes de 'Engenharia, Produção e Construção' e 'Ciências, Matemática e Computação', enquanto as áreas de 'Saúde e Bem-Estar Social', 'Agricultura e Veterinária' e 'Educação' apresentam os menores percentuais.

${ }^{19}$ A base de alunos matriculados no início do ano é maior no começo do curso, razão pela qual os anos iniciais representam a maior parte dos casos de abandono ou desligamento, mesmo com uma taxa de atrito menor. 


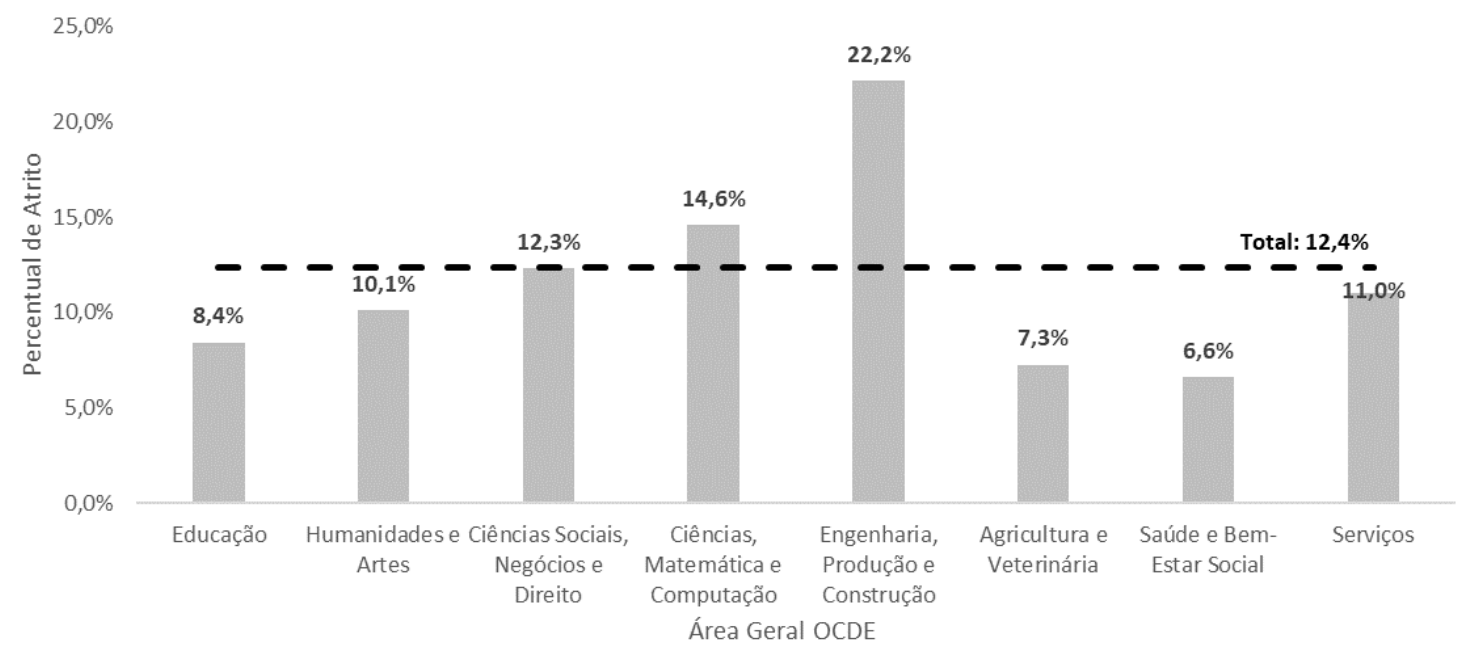

Gráfico 6. Taxa de atrito dos alunos de mestrado (na amostra) por grande área de conhecimento, conforme classificação da UNESCO (1997). Fonte: elaboração própria, com base em CAPES (2017a).

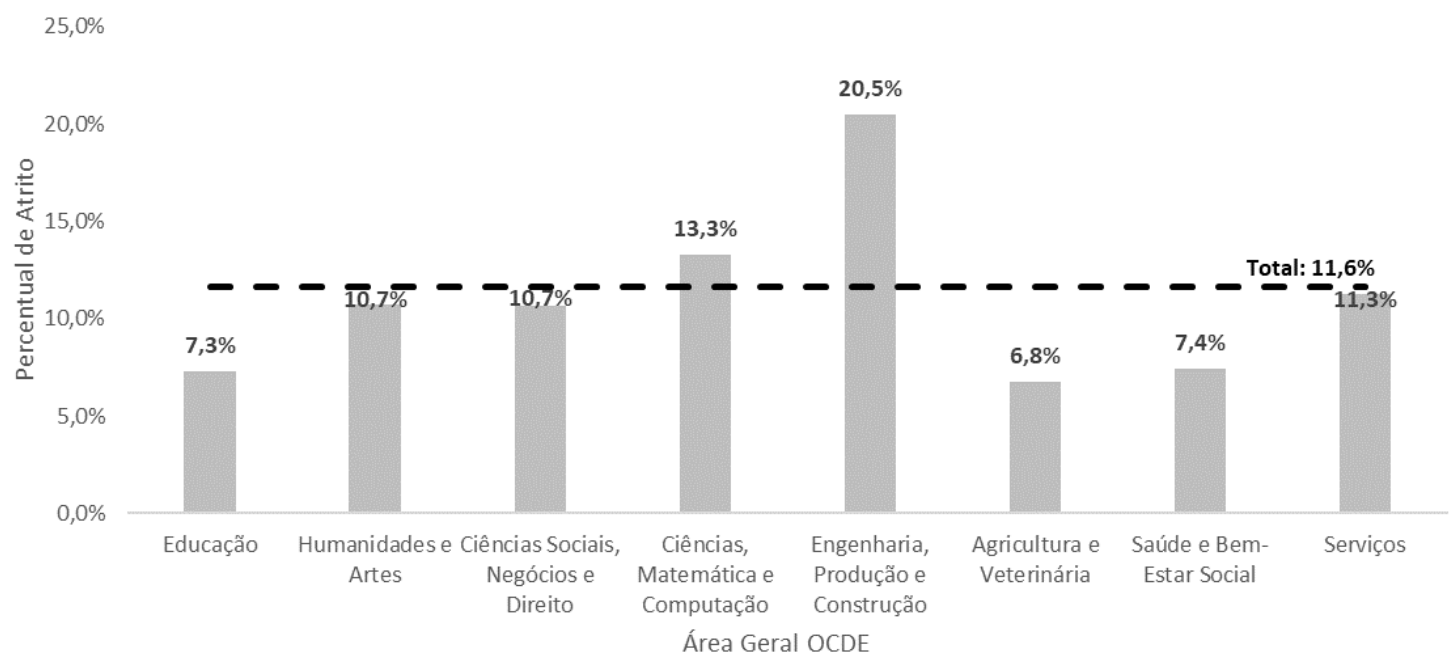

Gráfico 7. Taxa de atrito dos alunos de doutorado por grande área de conhecimento, conforme classificação da UNESCO (1997). Fonte: elaboração própria, com base em CAPES (2017a).

Os Gráficos 8 e 9 apresentam o percentual de alunos que concluíram o curso a cada ano, considerando apenas a amostra de alunos titulados ${ }^{20}$. No caso do mestrado, a maioria (aproximadamente $85 \%$ ) obteve a titulação até o final do terceiro ano após o ingresso, sendo residual a proporção daqueles que apenas receberam seus títulos após o quarto ano (inferior a 2\%). A grande área de 'Agricultura e Veterinária' apresenta o maior percentual de alunos titulados até o final do terceiro ano (aproximadamente 94\%), enquanto os cursos de 'Engenharia, Produção e Construção' possuem a menor proporção de titulados nesse intervalo (76\%). As mesmas grandes áreas se destacam também no doutorado: enquanto cerca de $85 \%$ dos alunos concluíram seus cursos até o término do quinto ano, esse percentual chega a $97 \%$ nos programas de 'Agricultura e Veterinária', mas atinge apenas 74\% dos estudantes de 'Engenharia, Produção e Construção’.

\footnotetext{
${ }^{20}$ Conforme exposto no item 4.1, foram excluídos da amostra os estudantes que receberam seus títulos no primeiro ano de mestrado e nos dois primeiros anos de doutorado.
} 


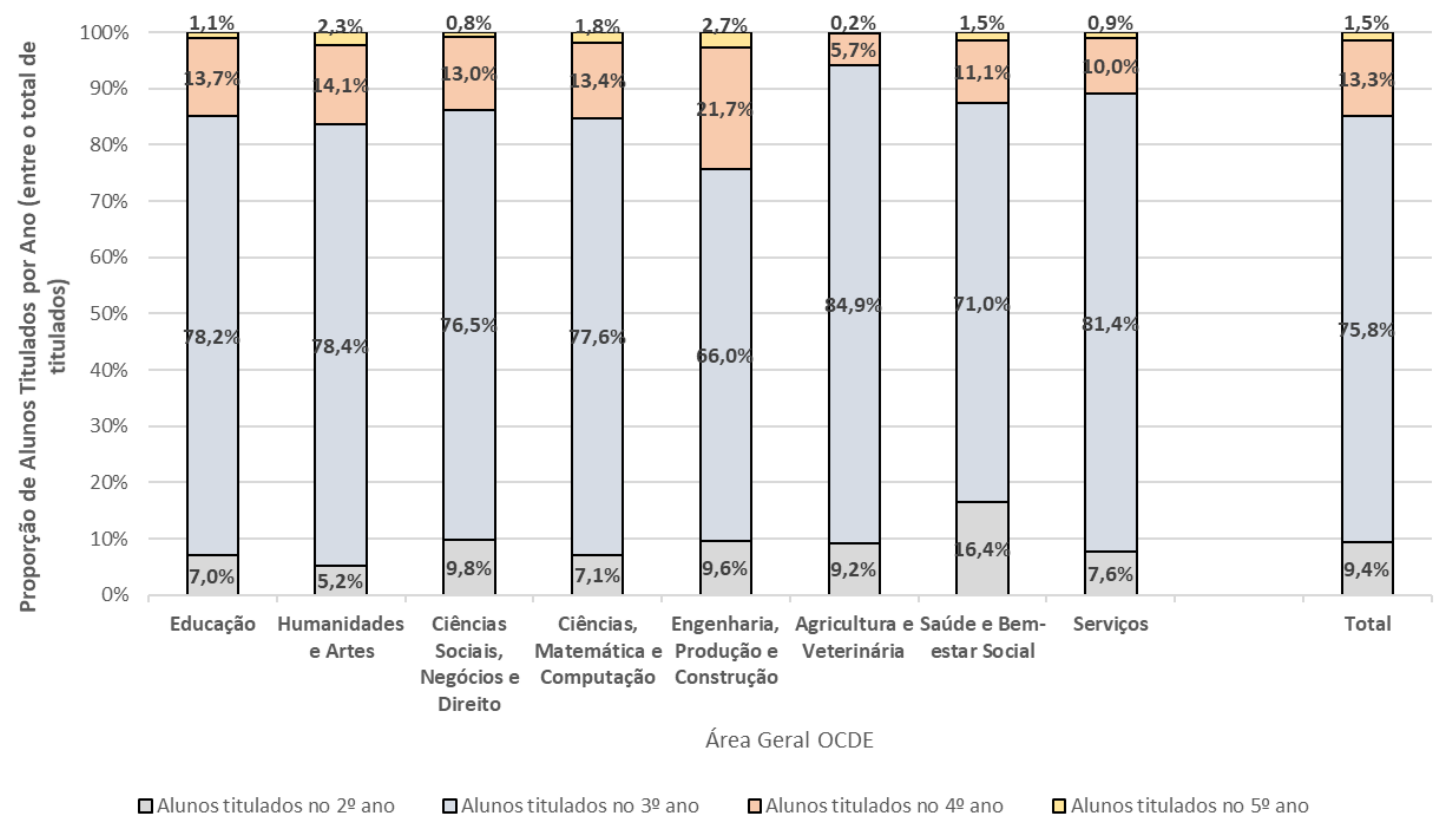

Gráfico 8. Percentual de alunos de mestrado titulados a cada ano após o ingresso (entre o total de titulados) por grande área de conhecimento, conforme classificação da UNESCO (1997). Fonte: elaboração própria, com base em CAPES (2017a).

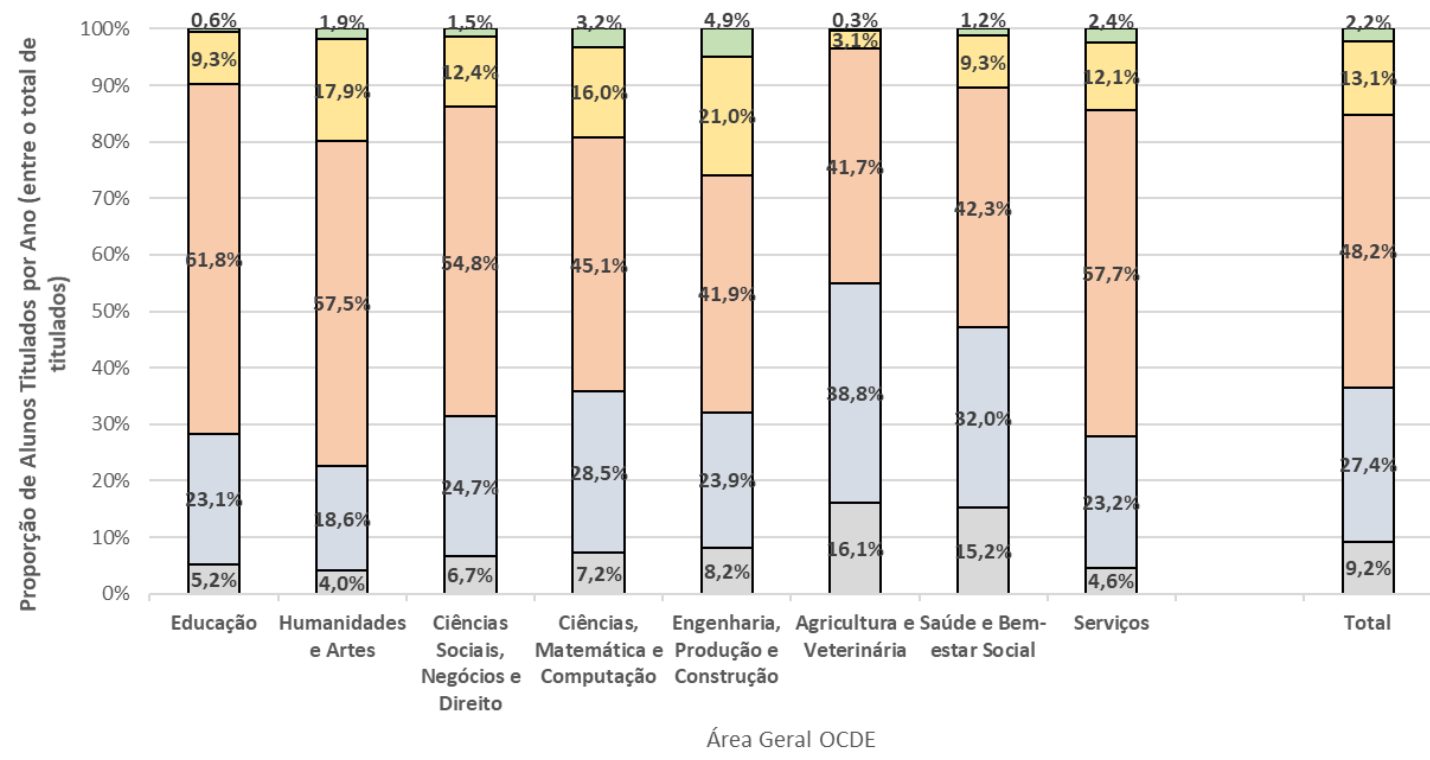

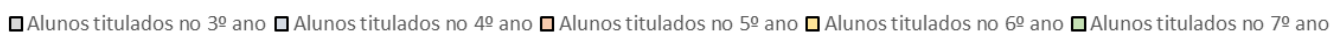

Gráfico 9. Percentual de alunos de doutorado titulados a cada ano após o ingresso (entre o total de titulados) por grande área de conhecimento, conforme classificação da UNESCO (1997). Fonte: elaboração própria, com base em CAPES (2017a).

Os dados brasileiros parecem destoar das principais conclusões apontadas pela literatura internacional acerca das áreas de conhecimento. Alunos das grandes áreas de 'Engenharias, Produção e Construção' e 'Ciências, Matemática e Computação' no Brasil apresentaram percentuais maiores de atrito e tempo de conclusão, ao contrário do observado em outros países (Abedi e Benkin, 1987; Zwick, 1991; Booth e Satchell, 1995; Groenvynck et al., 2013; Matute, 2014; Wollast et al., 2018). Além disso, os programas de 'Humanidades e Artes', 'Ciências Sociais Aplicadas, Negócios e Direito' ou 'Educação' não apresentaram números muito superiores à média nacional, o que também não se encontra alinhado à literatura empírica citada. 


\subsection{Análise das características pessoais: a trajetória dos estudantes por sexo e idade}

Neste subitem são estudadas duas características pessoais dos estudantes identificadas pela literatura internacional como fatores relevantes para explicar sua trajetória na pós-graduação. Inicialmente, a taxa de atrito e o tempo estimado para conclusão são investigados separando-se o corpo discente pelo sexo dos alunos, e em seguida por sua idade no ano de ingresso.

Conforme discutido na seção 2, homens e mulheres podem apresentar números distintos para esses indicadores devido às distintas proporção desses grupos em cada uma das áreas do conhecimento (Abedi e Benkin, 1987; Attiyeh, 1999; Groenvynck et al., 2013), conforme evidenciado em estudo prévio acerca do perfil dos pós-graduandos no país (Colombo, 2018). Questões familiares, as relações com professores e com outros colegas (Hagedorn, 1993), e as responsabilidades de criação dos filhos (Abedi e Benkin, 1987; Frasier, 2013) também são apontadas como possíveis causas das diferentes trajetórias entre os sexos. Outro argumento sugerido é o do 'vazamento na produção' (leaky pipeline), que utiliza a metáfora do processo produtivo para explicar a maior proporção de atrito entre mulheres nas carreiras científicas (Wakeling e Kyriacou, 2010; Cole e Espinoza, 2011) ${ }^{21}$.

Os dados para a amostra de estudantes brasileiros agrupados por sexo são apresentados no Gráficos 10 e 11, separando-os por grandes áreas de conhecimento. Em todos os casos observa-se uma taxa de atrito superior para homens, havendo uma diferença mais pronunciada nas grandes áreas de 'Engenharias, Produção e Construção' e 'Ciências, Matemática e Computação'. Novamente, esse resultado parece não seguir aqueles observados em outros países, onde não foram identificadas diferenças significativas entre os sexos, ou mesmo foram encontradas taxa de atrito ligeiramente inferiores para homens (Zwick, 1991; Attiyeh, 1999; Visser et al., 2007; Jiranek, 2010; Wollast et al., 2018). As razões que explicam essa discrepância em todas as grandes áreas de conhecimento é outro ponto que merece ser investigado em maior detalhe em futuras pesquisas.

Por outro lado, não parece haver diferença expressiva entre sexos no tempo para conclusão dos cursos, conforme apresentado na Tabela 2. Em todas as grandes áreas, o tempo médio de titulação de homens e mulheres é similar. Neste aspecto, o caso brasileiro parece mais próximo da tendência apontada para outros países, nos quais o sexo dos estudantes não foi identificado como um elemento explicativo do tempo para titulação (Siegfried e Stock, 2001; Spronken-Smith et al., 2018).

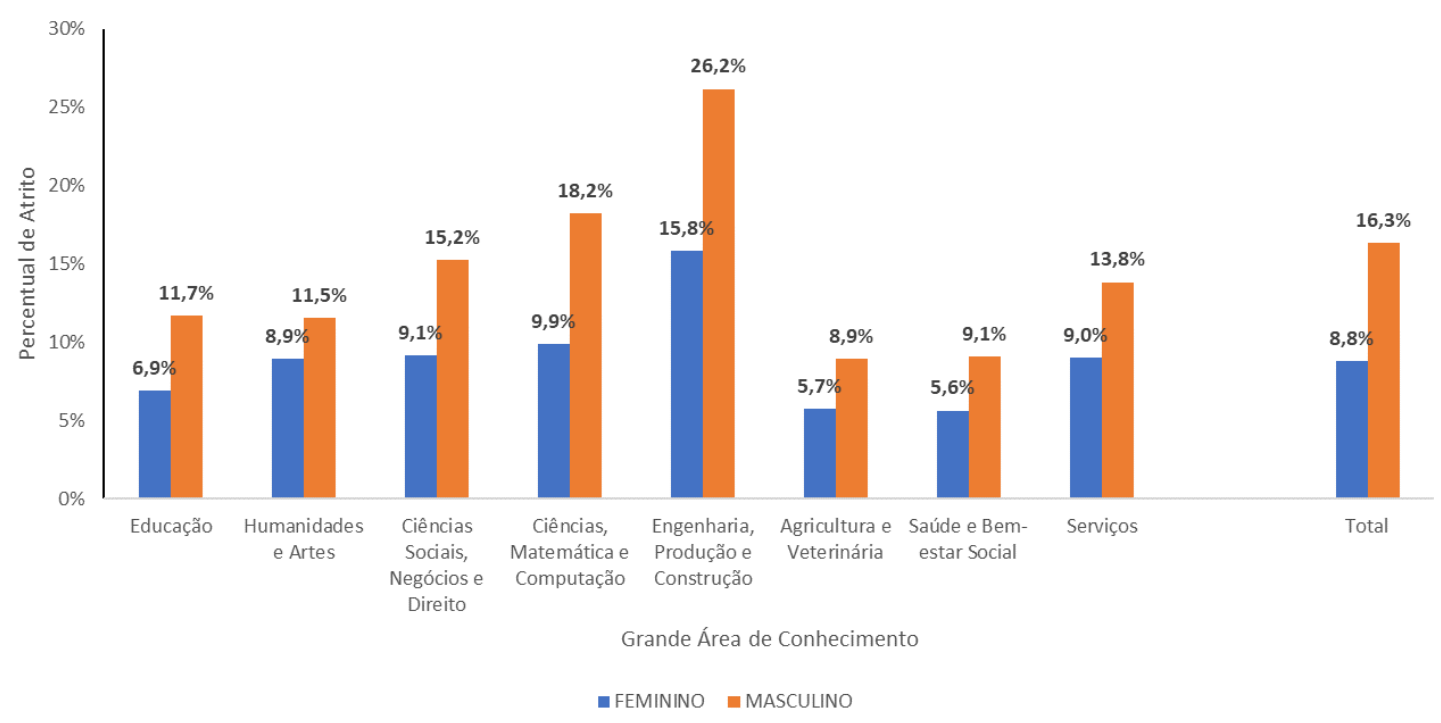

Gráfico 10. Taxa de atrito no mestrado, por sexo e grande área de conhecimento, conforme classificação da UNESCO (1997). Fonte: elaboração própria, com base em CAPES (2017a).

\footnotetext{
${ }^{21}$ Esse argumento, contudo, é criticado por tratar os alunos como agentes passivos em seu processo educacional, e por não ser capaz de explicar porque um grupo de estudantes 'vaza' mais do que outros (Herzig, 2004).
} 


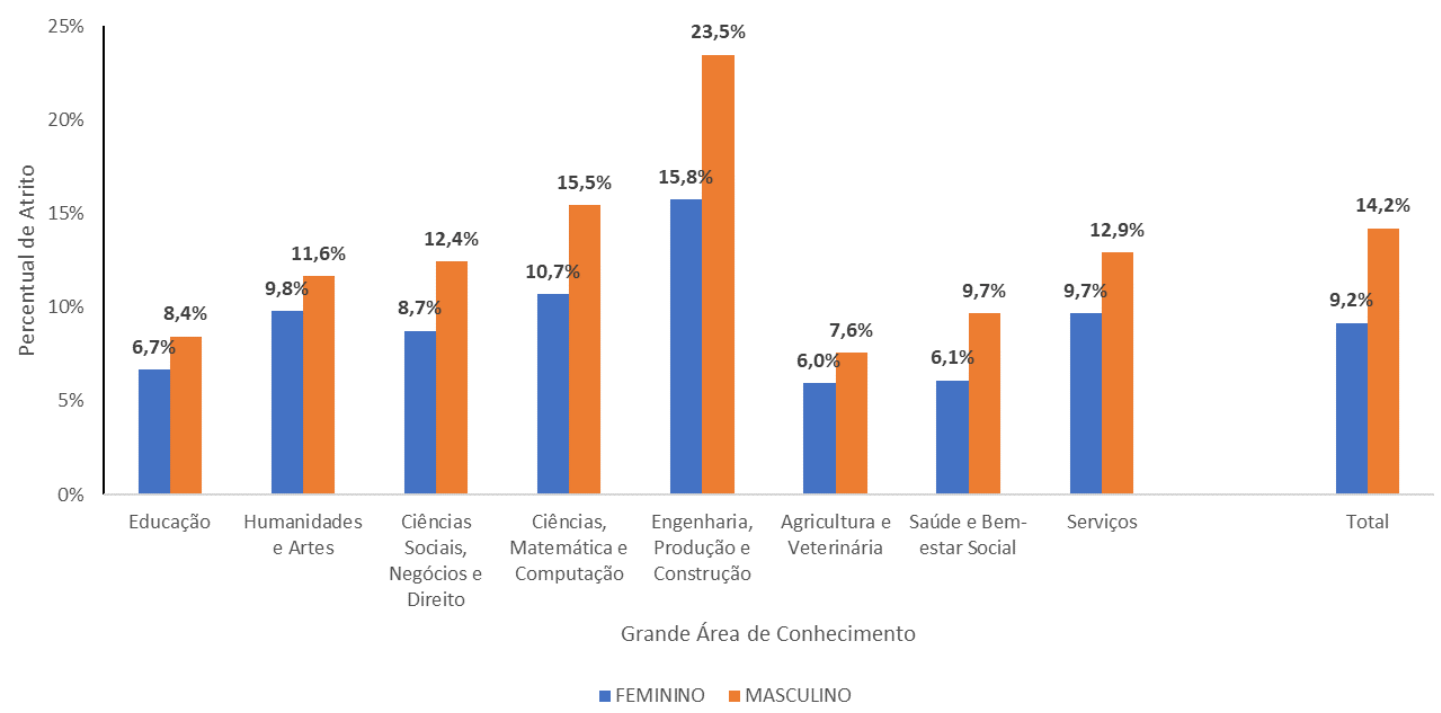

Gráfico 11. Taxa de atrito no doutorado, por sexo e grande área de conhecimento, conforme classificação da UNESCO (1997). Fonte: elaboração própria, com base em CAPES (2017a).

Tabela 2. Tempo médio de conclusão do mestrado e doutorado (em anos a partir do ingresso) entre os alunos titulados (na amostra), por sexo e grande área de conhecimento, conforme classificação da UNESCO (1997).

\begin{tabular}{|c|c|c|c|c|}
\hline \multirow{3}{*}{$\begin{array}{l}\text { Grande Área de Conhecimento } \\
\text { (UNESCO, 1997) }\end{array}$} & \multicolumn{4}{|c|}{ Tempo Médio de Conclusão (em anos a partir do ingresso) } \\
\hline & \multicolumn{2}{|c|}{ Mestrado } & \multicolumn{2}{|c|}{ Doutorado } \\
\hline & Feminino & Masculino & Feminino & Masculino \\
\hline Educação & 3,1 & 3,1 & 4,6 & 4,6 \\
\hline Humanidades e Artes & 3,1 & 3,1 & 4,7 & 4,6 \\
\hline Ciências Sociais, Negócios e Direito & 3,0 & 3,0 & 4,6 & 4,5 \\
\hline Ciências, Matemática e Computação & 3,1 & 3,1 & 4,5 & 4,4 \\
\hline Engenharia, Produção e Construção & 3,2 & 3,2 & 4,5 & 4,4 \\
\hline Agricultura e Veterinária & 3,0 & 3,0 & 4,3 & 4,2 \\
\hline Saúde e Bem-estar Social & 3,0 & 3,0 & 4,3 & 4,3 \\
\hline Serviços & 3,0 & 3,1 & 4,6 & 4,6 \\
\hline Total & 3,1 & 3,1 & 4,5 & 4,4 \\
\hline$N$ & 142.909 & 114.976 & 25.995 & 22.332 \\
\hline
\end{tabular}

Fonte: elaboração própria, com base em CAPES (2017a).

O segundo atributo pessoal considerado é a idade dos estudantes no momento do ingresso no curso. Diferentes explicações foram levantadas para sugerir os motivos pelos quais essa variável deve influenciar a trajetória dos estudantes, com impactos distintos ou ambíguos. Por um lado, estudantes mais jovens possuem maior entusiasmo, além de habilidades e conhecimentos mais atualizados, reduzindo o tempo necessário para cumprir atividades acadêmicas; por outro, alunos mais velhos encaram um custo de oportunidade de estudo maior e um horizonte temporal reduzido para extrair benefícios do título de mestre ou doutor, o que os levaria a concluir o curso mais rápido e com menor probabilidade de abandono ou desligamento (Siegfried e Stock, 2001). Ainda assim, diferentes estudos para outros países (Estados Unidos, Bélgica e Reino Unido) encontraram uma taxa de sucesso mais elevada entre estudantes de doutorado mais jovens (Park, 2005; Cohen, 2012; Wollast et al., 2018), muito embora Bair e Haworth (2004), em sua metaanálise no tema, não identificaram a idade como um variável significante para explicar a persistência no doutorado. 
Os Gráficos 12 e 13 agrupam os estudantes por idade no ano de ingresso no curso (no eixo horizontal), apresentando o percentual de atrito através do marcador azul e no eixo vertical esquerdo, e o tempo médio de conclusão entre os titulados através do marcador laranja e no eixo vertical direito. Assim como no caso do sexo dos alunos, os dados fornecem indícios de que a idade pode influenciar o atrito ou persistência, mas não o tempo médio para conclusão, tanto no caso do mestrado quanto do doutorado.

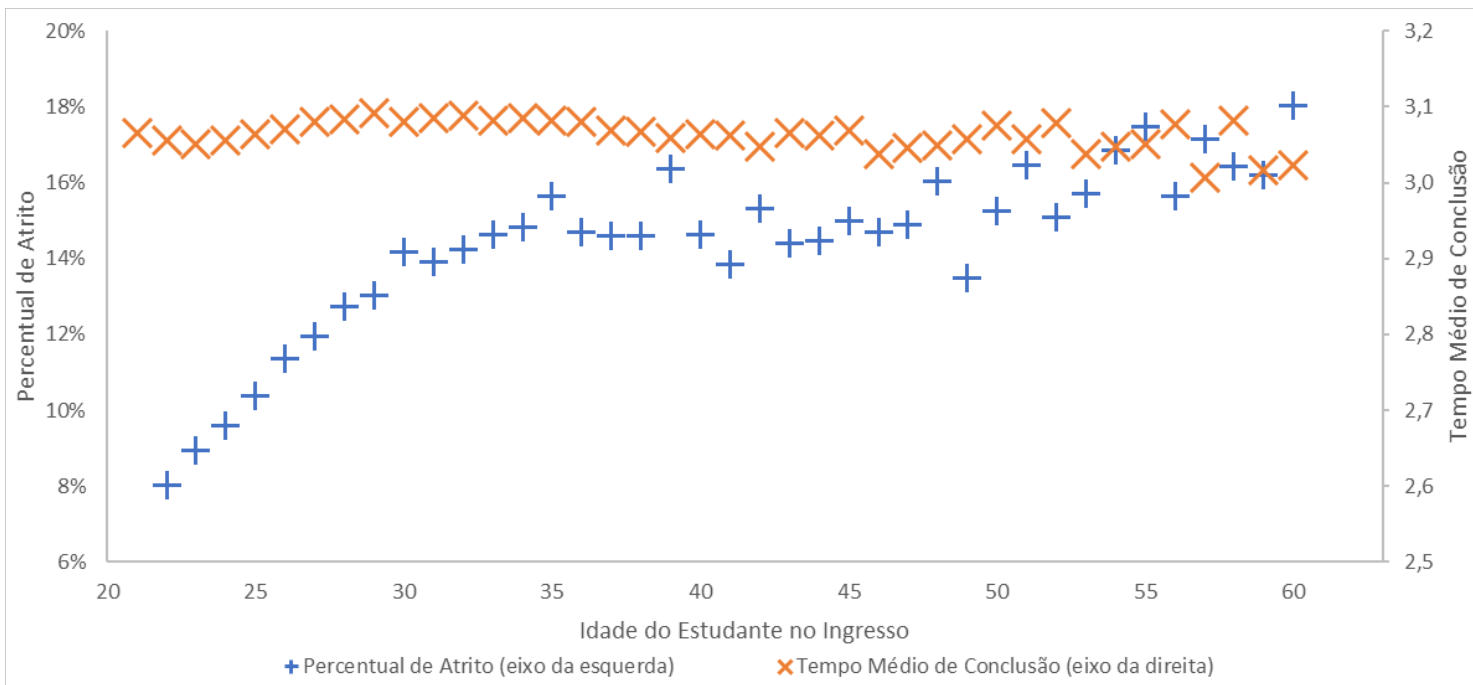

Gráfico 12. Taxa de atrito e tempo médio de conclusão no mestrado (entre os alunos titulados), por idade no ingresso. Fonte: elaboração própria, com base em CAPES (2017a).

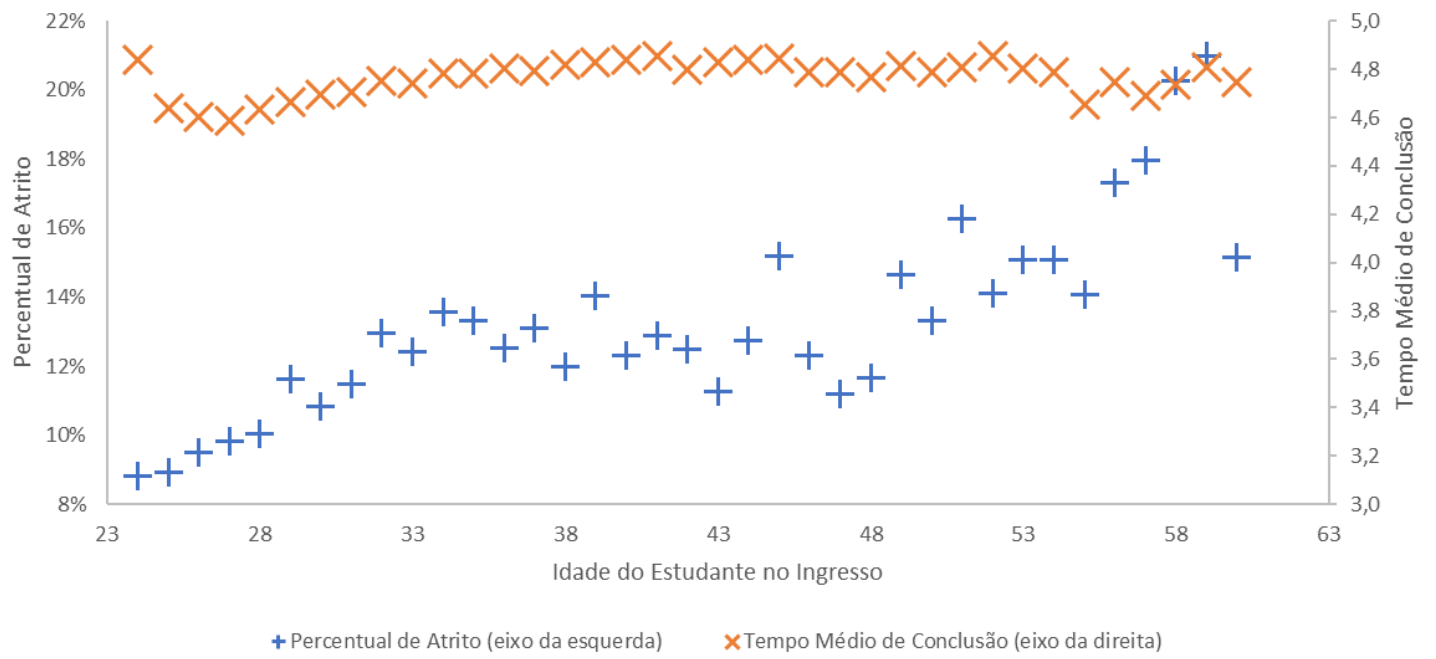

Gráfico 13. Taxa de atrito e tempo médio de conclusão no doutorado (entre os alunos titulados), por idade no ingresso. Fonte: elaboração própria, com base em CAPES (2017a).

Observa-se uma taxa de atrito menor entre estudantes mais jovens de ambos os cursos. No caso do mestrado, essa taxa encontra-se em torno de $9 \%$ entre aqueles que ingressaram no mestrado entre os $22 \mathrm{e}$ 23 anos (que representam os casos daqueles que progrediram para esse nível educacional imediatamente ou pouco tempo depois da graduação). Esse percentual sofre uma elevação expressiva e uniforme até o grupo dos alunos que ingressaram com 30 anos, atingindo cerca de $14 \%$ de atrito, sugerindo que a idade provavelmente constitua um elemento explicativo relevante para explicar o abandono ou desligamento nessa faixa etária. Por outro lado, após os 30 anos, o percentual de atrito cresce de maneira mais suave e com uma dispersão maior, indicando que outros fatores devem influenciar com maior ênfase a escolha dos estudantes pela continuidade dos seus cursos. Algo similar ocorre no caso dos cursos de doutorado, nos quais se observa um atrito crescente e relativamente uniforme no intervalo dos alunos que ingressaram dos 24 aos 32 anos, havendo uma dispersão maior após esse período. 


\subsection{Análise de atributos institucionais: a natureza jurídica da instituição e qualidade do curso}

Características do curso e da universidade podem afetar a trajetória do aluno de mestrado e doutorado de diferentes formas, seja influenciando a integração do estudante ao ambiente acadêmico, ou determinando os custos, o esforço necessário para aprovação e o retorno esperado. Em uma primeira análise que busca compreender a importância desses aspectos, são avaliadas duas variáveis institucionais, para levantar indícios sobre como elas podem influenciar as escolhas dos estudantes brasileiros.

Em primeiro lugar, considera-se a natureza jurídica das instituições de ensino, distinguindo-as entre públicas e privadas. Tal distinção é particularmente relevante devido aos custos e taxas: enquanto instituições privadas podem estabelecer mensalidades a serem pagas por seus estudantes, universidades públicas estão proibidas de realizar essa cobrança, conforme decisão recente do Supremo Tribunal Federal que confirmou esse entendimento (STF, 2017). O pagamento de taxas afeta os custos percebidos pelos alunos, podendo, por exemplo, reduzir o tempo em que eles planejam concluir o curso (como sugerido por Breneman, 1976) ou inviabilizar sua permanência em caso de ausência de financiamento ou desemprego.

Os dados para a amostra resumidos nos Gráficos 14 e 15 indicam uma maior taxa de atrito entre os estudantes de instituições privadas, tanto no mestrado quanto no doutorado, com uma diferença de aproximadamente 3 pontos percentuais (p.p.) em ambos os casos (as únicas exceções são os cursos de mestrado e doutorado em 'Engenharia, Produção e Construção' e os de doutorado em 'Agricultura e Veterinária'). As maiores diferenças de percentual de abandono ou desligamento para instituições privadas são encontradas nos cursos de mestrado em 'Serviços', e de mestrado e doutorado em 'Ciências, Matemática e Computação'.

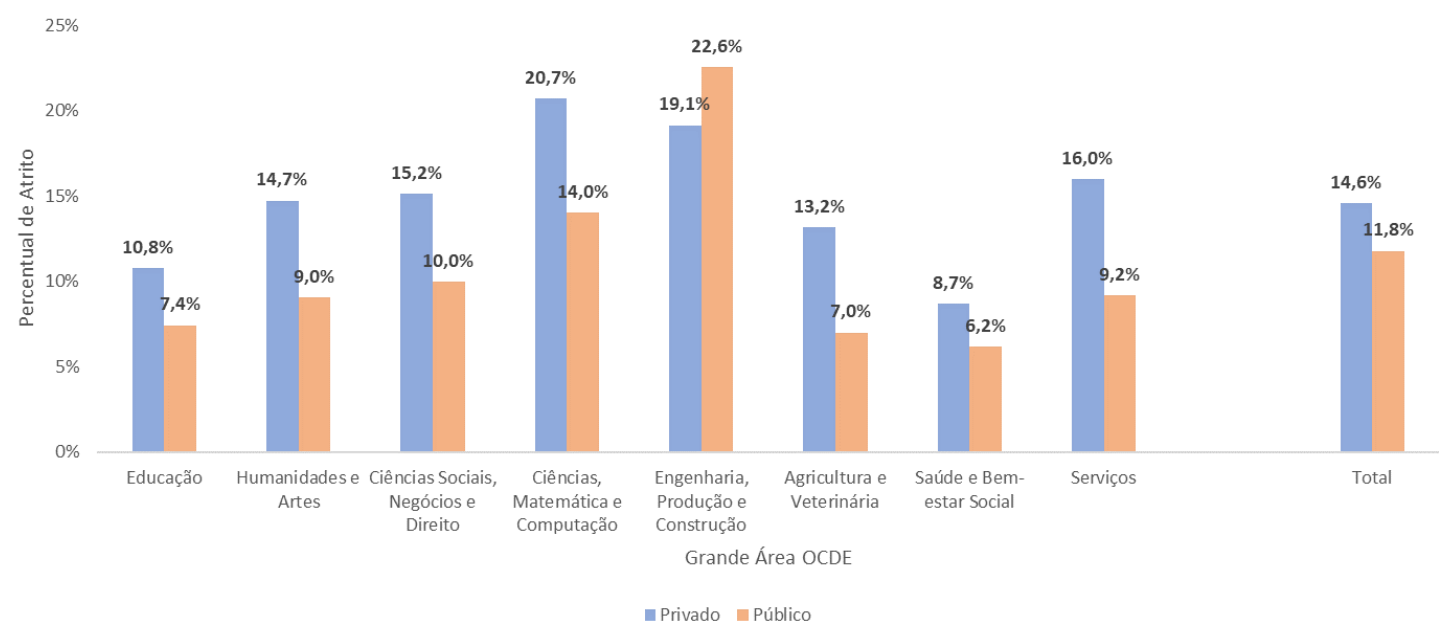

Gráfico 14. Taxa de atrito no mestrado, por natureza jurídica da instituição de ensino e por grande área de conhecimento, conforme classificação da UNESCO (1997). Fonte: elaboração própria, com base em CAPES (2017a). 


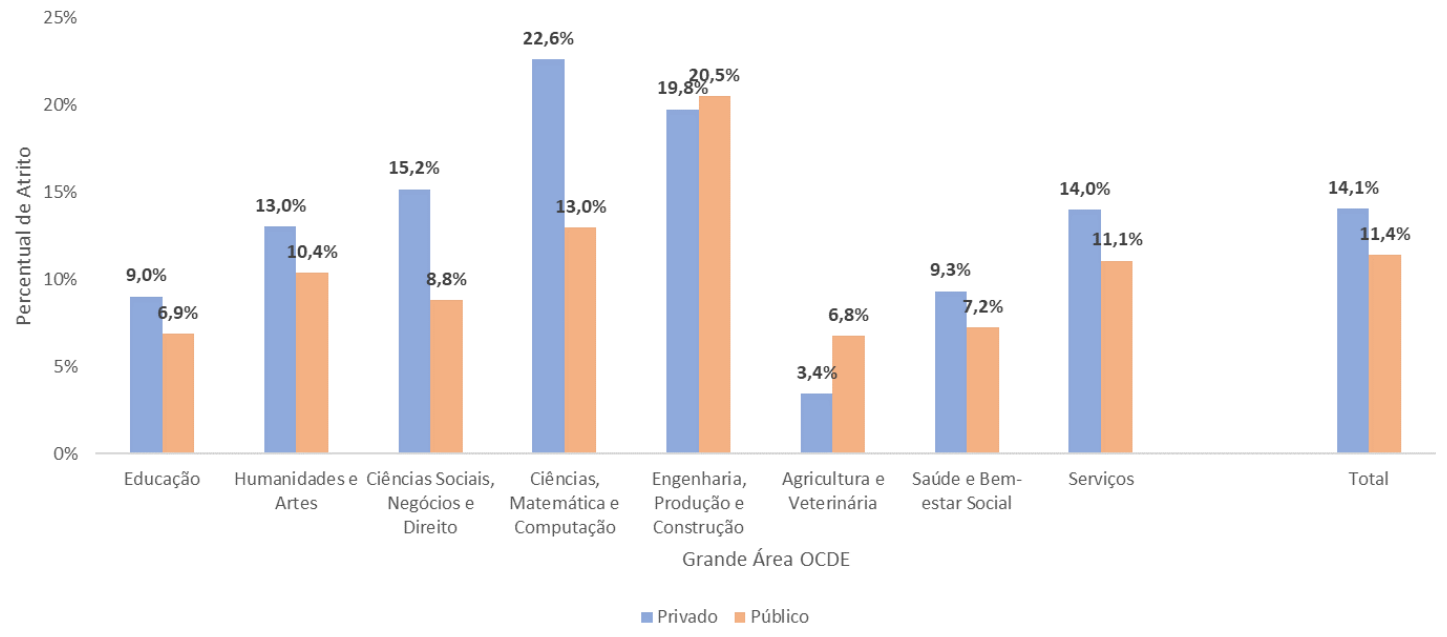

Gráfico 15. Taxa de atrito no doutorado, por natureza jurídica da instituição de ensino e grande área de conhecimento, conforme classificação da UNESCO (1997). Fonte: elaboração própria, com base em CAPES (2017a).

Por outro lado, a natureza jurídica da instituição parece ter pouca ou nenhuma influência sobre o tempo que os alunos levam para concluir suas atividades e obter o título. A Tabela 3 indica que a média do tempo que estudantes em ambos os tipos de instituição levaram para concluir o curso é muito próxima, tanto para o total de estudantes quanto nas diferentes grandes áreas de conhecimento.

Tabela 3. Tempo médio de conclusão do mestrado e doutorado (em anos a partir do ingresso) entre os alunos titulados (na amostra), por natureza jurídica da instituição de ensino e grande área de conhecimento, conforme classificação da UNESCO (1997).

\begin{tabular}{|c|c|c|c|c|}
\hline \multirow{3}{*}{ Grande Área de Conhecimento } & \multicolumn{4}{|c|}{ Tempo Médio de Conclusão (em anos a partir do ingresso) } \\
\hline & \multicolumn{2}{|c|}{ Mestrado } & \multicolumn{2}{|c|}{ Doutorado } \\
\hline & Privado & Público & Privado & Público \\
\hline Educação & 3,1 & 3,1 & 4,6 & 4,6 \\
\hline Humanidades e Artes & 3,1 & 3,1 & 4,6 & 4,7 \\
\hline Ciências Sociais, Negócios e Direito & 3,0 & 3,1 & 4,5 & 4,6 \\
\hline Ciências, Matemática e Computação & 3,1 & 3,1 & 4,5 & 4,5 \\
\hline Engenharia, Produção e Construção & 3,2 & 3,2 & 4,4 & 4,5 \\
\hline Agricultura e Veterinária & 3,0 & 3,0 & 4,0 & 4,3 \\
\hline Saúde e Bem-estar Social & 2,8 & 3,0 & 4,3 & 4,3 \\
\hline Serviços & 3,0 & 3,1 & 4,5 & 4,6 \\
\hline Total & 3,0 & 3,1 & 4,5 & 4,5 \\
\hline$N$ & 52.098 & 206.787 & 4.682 & 43.645 \\
\hline
\end{tabular}

Fonte: elaboração própria, com base em CAPES (2017a).

A última variável considerada neste estudo é a qualidade ou excelência do curso, medida através da nota obtida na avaliação da CAPES (conforme descrito na seção 3), considerando o ano de ingresso do aluno ou a avaliação mais recente (CAPES, 2018). Esse atributo pode afetar a decisão e a trajetória dos alunos de diferentes formas, não sendo óbvio o sentido desse efeito. Por um lado, cursos de maior excelência podem exigir um esforço adicional de seus alunos para a obtenção do título, elevando o custo do estudo e estimulando um maior nível de atrito. Além disso, a competição entre estudantes em cursos de maior qualidade pode afetar negativamente a integração, também contribuindo para o abandono ou desligamento. Em sentido contrário, seguindo a teoria de sinalização (Spence, 1979), cursos com avaliação e reputação mais elevadas podem apresentar retornos financeiros e profissionais esperados maiores a seus 
alunos ou elevar a sua satisfação com o programa (Bair e Haworth, 2004), servindo como um estímulo à persistência. A evidência empírica no tema é reduzida: dois estudos entre alunos de doutorado nos Estados Unidos concluíram que alunos de instituições mais seletivas ou de qualidade elevada (segundo a percepção dos estudantes) tendem a persistir mais (Valentine, 1987; Attiyeh, 1999).

No caso das instituições brasileiras, os dados (Gráfico 16) sugerem que essa variável parece afetar de maneira distinta a taxa de atrito nos dois níveis acadêmicos. No caso do mestrado, as menores taxas de atrito são observadas entre os alunos de cursos com nota intermediária (entre quatro e seis), enquanto aqueles que estudam nos cursos com notas maiores ou menores apresentam proporções maiores de abandono ou desligamento (em torno de 15\%). Esses números indicam que a qualidade do curso pode afetar o atrito na pós-graduação por diferentes canais e em direções distintas, e o efeito preponderante varia de acordo com a qualidade do curso em questão. Por outro lado, no doutorado observa-se uma relação negativa mais clara entre a qualidade do curso e a taxa de atrito: a proporção de abandono ou desligamento é maior entre os alunos dos cursos com menor nota (conceito 3), havendo pouca diferença entre aqueles que estudam em cursos com conceito mais elevado (entre 5 e 7 ).

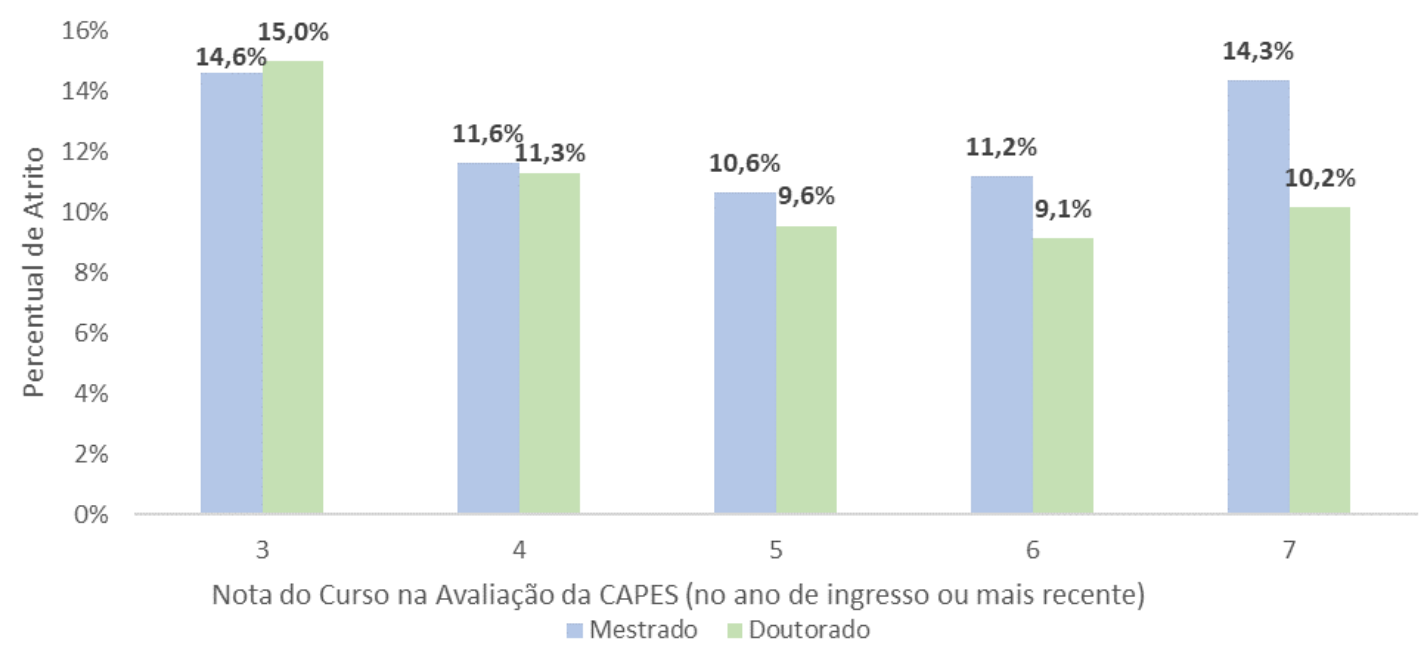

Gráfico 16. Taxa de atrito no mestrado e doutorado, por conceito do curso obtido na avaliação da CAPES, considerando o ano de ingresso do aluno (ou avaliação mais recente). Fonte: elaboração própria, com base em CAPES (2017a; 2018).

O tempo para conclusão do curso também apresenta distribuição distinta por conceito para os níveis de mestrado e doutorado. Alunos de mestrado (Gráfico 17) de maior excelência na avaliação da CAPES levam um tempo médio maior para obtenção do título: enquanto $85 \%$ dos alunos titulados em cursos com conceito de três a cinco concluem seus estudos em até três anos, a proporção é reduzida em 10 p.p. para os cursos com as maiores notas (seis e sete). No doutorado (Gráfico 18), as distribuições de tempo médio de conclusão são mais próximas, mas novamente sugerem que os efeitos da qualidade podem não ser lineares ou unidirecionais: alunos de cursos com as menores e maiores notas (conceitos iguais a três e sete) apresentam percentuais menores e aproximados de titulação até o quinto ano após o ingresso, enquanto os cursos com avaliação intermediária (nota cinco) possuem uma proporção maior de alunos titulados nesse período. 

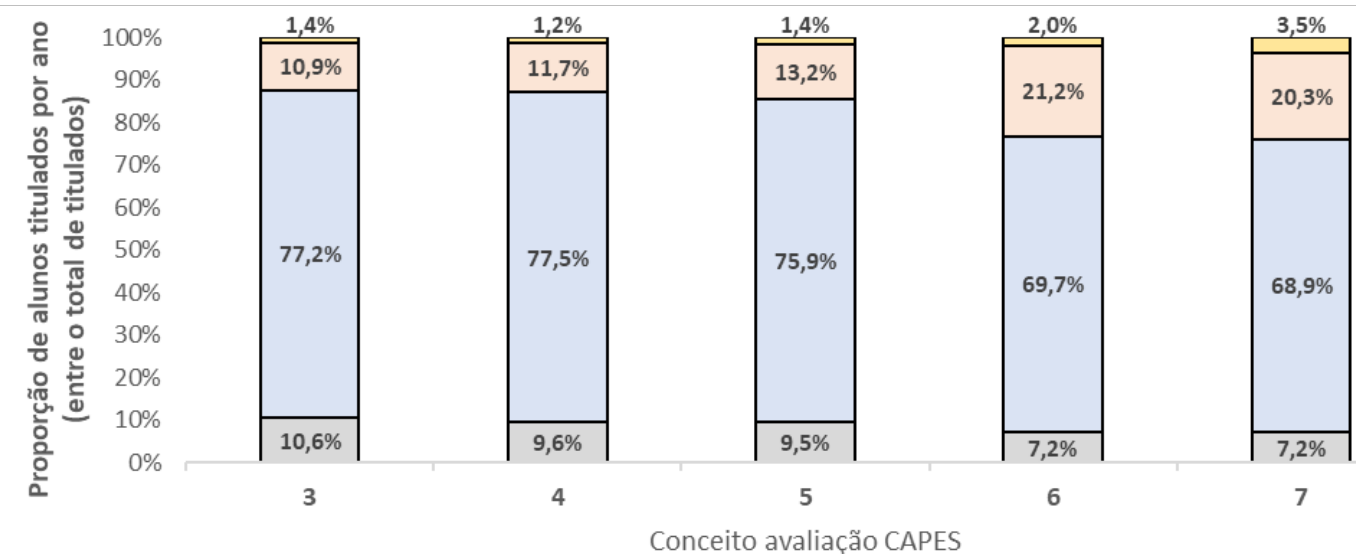

Conceito avaliação CAPES

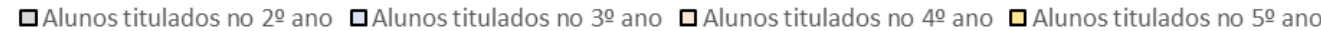

Gráfico 17. Percentual de alunos de mestrado titulados a cada ano (entre o total de titulados), por ano após o ingresso e nota do curso na avaliação da CAPES (considerando o ano de ingresso do aluno ou a avaliação mais recente). Fonte: elaboração própria, com base em CAPES (2017a; 2018).

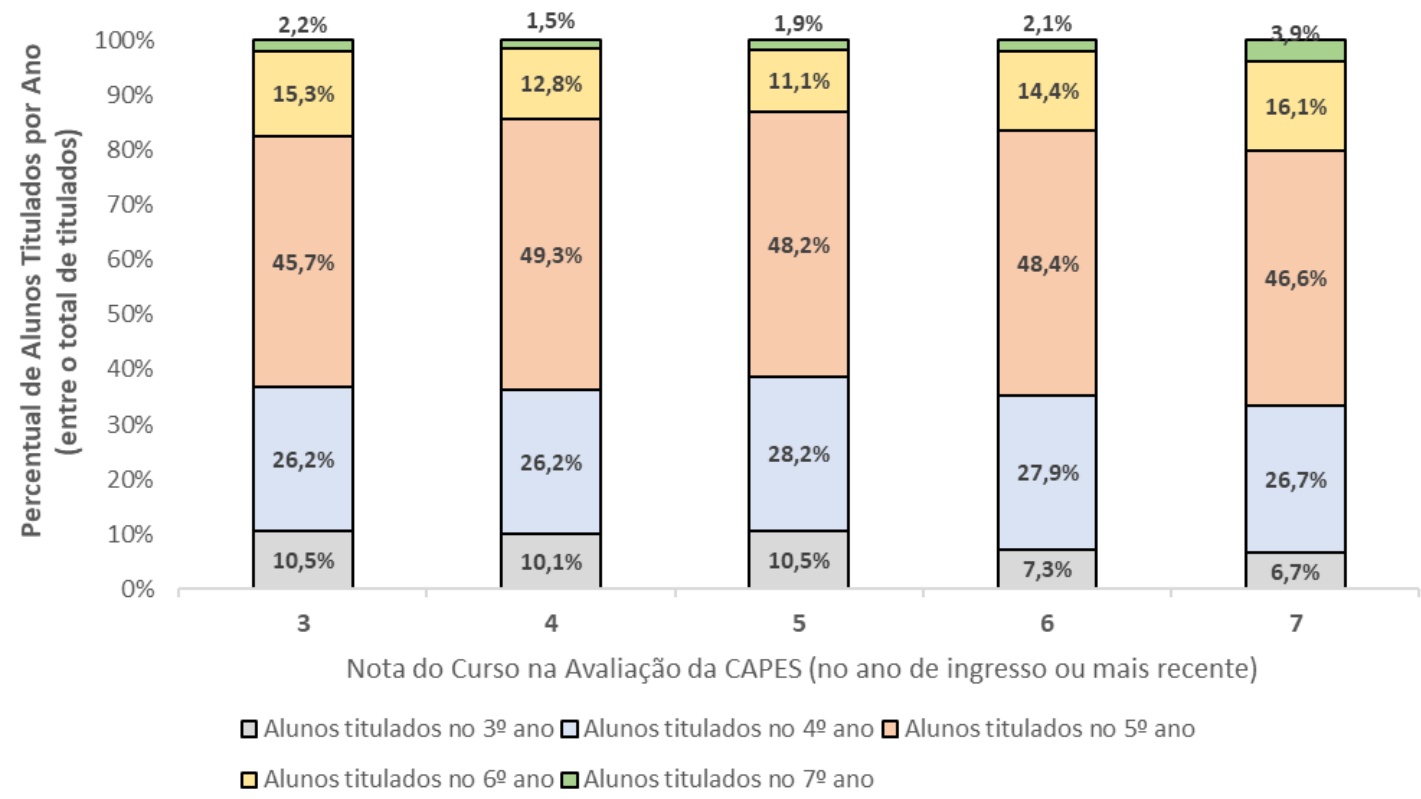

Gráfico 18. Percentual de alunos de doutorado titulados a cada ano (entre o total de titulados), por ano após o ingresso e nota do curso na avaliação da CAPES (considerando o ano de ingresso do aluno ou a avaliação mais recente). Fonte: elaboração própria, com base em CAPES (2017a; 2018).

Esta seção trouxe e discutiu dados acerca da trajetória dos estudantes de mestrado e doutorado em instituições brasileiras. Foram apresentadas informações acerca dos períodos em que esses alunos concluem e abandonam (ou se desligam de) seus cursos, investigando-se ainda as diferenças nesses indicadores por grandes áreas de conhecimento. Além disso, foi possível observar que as trajetórias educacionais na pósgraduação variam e parecem estar relacionadas com as características pessoais e institucionais dos estudantes e de seus cursos.

Conforme destacado, esses dados iniciais devem ser compreendidos como um primeiro grupo de indícios de como esses fatores podem predizer ou impactar as decisões dos estudantes, não constituindo evidência desse efeito. Nesse sentido, este trabalho abre uma relevante agenda de pesquisa para a elaboração de estudos que busquem testar e explicar como essas e outras variáveis afetam tais escolhas, assim como a magnitude desses efeitos, através da formulação de modelos empíricos que considerem e controlem por diversos fatores conjuntamente. 


\section{Considerações finais}

Este artigo apresentou uma primeira análise acerca da trajetória dos alunos de pós-graduação stricto sensu brasileiros, descrevendo os principais marcos teóricos no tema e dando ênfase ao atrito e ao tempo para conclusão dos cursos. A literatura internacional nesses assuntos é recente, mas conta com um acúmulo de proposições e evidências que permite formular hipóteses sobre como diferentes fatores pessoais e institucionais podem afetar as escolhas dos estudantes. A discussão sobre essas questões no país é praticamente inexistente, mas o caso brasileiro constitui uma oportunidade para a pesquisa acerca da pósgraduação, devido ao número de alunos e à existência de uma base de dados nacional com informações sobre eles.

A pós-graduação brasileira desenvolveu-se e passou por muitas mudanças nas últimas décadas. A expansão dos cursos alterou o perfil do corpo discente de mestrado e doutorado, incluindo a distribuição dos alunos por sexo e idade. Além disso, a proporção de estudantes por cada grande área do conhecimento também mudou, o que pode ter impacto na persistência e no tempo de titulação. E o arcabouço institucional foi modificado e atualizado, principalmente pela atuação da CAPES, trazendo mudanças quanto ao financiamento e avaliação dos cursos com potenciais reflexos nas trajetórias estudantis.

A análise dos dados brasileiros indicou que as instituições brasileiras possuem taxas de atrito em torno de $12 \%$, número relativamente baixo se comparado com aqueles observados em outros países (Park, 2005; Ampaw e Jaeger, 2012). A proporção tende a aumentar com o tempo do aluno no curso, sugerindo que aqueles que levam mais tempo para concluir seus estudos possuem um risco maior de abandono ou desligamento. Além disso, foram observadas taxas de atrito inferiores para mulheres, alunos mais jovens e estudantes de instituições públicas no mestrado e no doutorado. Já a avaliação ou qualidade do curso apresenta uma relação ambígua com a taxa de atrito, demandando uma investigação mais aprofundada.

A maior parte (pouco mais de 70\%) dos alunos titulados no mestrado concluí o curso até o fim do terceiro ano após o ingresso, enquanto no doutorado esse percentual se observa até o fím do quinto ano. Ao contrário da taxa de atrito, não foram observados indícios de que o sexo, a idade dos estudantes e a natureza jurídica das instituições de ensino afetem de maneira substancial o tempo para conclusão do curso. Por outro lado, os cursos de mestrado mais bem avaliados apresentam as menores proporções de alunos que concluem em até três anos, enquanto a relação parece ambígua no caso do doutorado.

Este trabalho sugere diferentes questões de pesquisa e pontos para ampliar a compreensão da trajetória dos estudantes de pós-graduação no Brasil. $\mathrm{O}$ avanço mais importante parece se referir ao aprimoramento dos dados existentes, especialmente nos casos em que a trajetória dos alunos apresenta-se incompleta (deixam de constar na base sem informação acerca do ocorrido para o encerramento do curso), e incorporando dados sobre o financiamento ou recebimento de bolsas, sejam elas concedidas por instituições federais, estaduais ou privadas.

Além disso, este trabalho apresenta dados iniciais e indícios de como as características pessoais e atributos institucionais podem afetar a trajetória dos estudantes, sendo necessária a formulação e estimação de modelos empíricos que testem o efeito dessas variáveis no atrito e tempo para conclusão dos cursos. Por fim, também é importante que pesquisas teóricas ou qualitativas tentem explicar os motivos pelos quais essas variáveis podem estar relacionadas às escolhas dos estudantes, especialmente nos casos em que os dados para o Brasil parecem destoar das conclusões apontadas em estudos internacionais.

\section{Referências}

Abedi, J.; Benkin, E. The effects of students' academic, financial, and demographic variables on time to the doctorate. Research in Higher Education, v. 27, n. 1, p. 3-14, 1987. ISSN 0361-0365.

Ali, A.; Kohun, F.; Levy, Y. Dealing with Social Isolation to Minimize Doctoral Attrition- A Four Stage Framework. International Journal of Doctoral Studies, v. 2, n. 1, p. 33-49, 2007.

Ampaw, F. D.; Jaeger, A. J. Completing the three stages of doctoral education: An event history analysis. Research in Higher Education, v. 53, n. 6, p. 640-660, 2012. ISSN 0361-0365. 
ANDIFES; ABRUEM; MEC. Diplomação, Retenção e Evasão nos Cursos de Graduação em Instituições de Ensino Superior Públicas. Brasilia 1996.

Araújo-Jorge, T. C. d.; Borba, M. d. C.; Sovierzoski, H. H. Documento de Área: Ensino. CAPES. Brasilia 2016.

Attiyeh, G. M. Determinants of persistence of graduate students in Ph. D. programs. ETS Research Report Series, v. 1999, n. 1, p. i-43, 1999. ISSN 2330-8516.

Bair, C. R.; Haworth, J. G. Doctoral student attrition and persistence: A meta-synthesis of research. In: (Ed.). Higher education: Handbook of theory and research: Springer, 2004. p.481-534.

Becker, G. S. Human capital revisited. In: (Ed.). Human Capital: A Theoretical and Empirical Analysis with Special Reference to Education (3rd Edition): The University of Chicago Press, 1994. p.15-28.

. Human Capital: A Theoretical and Empirical Analysis, with Special Reference to Education. University of Chicago Press, 2009. ISBN 9780226041223. Disponível em: < https://books.google.com.br/books?id=9t69iICmrZ0C $>$.

Beekhoven, S.; De Jong, U.; Van Hout, H. Explaining academic progress via combining concepts of integration theory and rational choice theory. Research in Higher Education, v. 43, n. 5, p. 577-600, 2002. ISSN 0361-0365.

Booth, L. L.; Satchell, S. E. The hazards of doing a PhD: an analysis of completion and withdrawal rates of British PhD students in the 1980s. Journal of the Royal Statistical Society: Series A (Statistics in Society), v. 158, n. 2, p. 297-318, 1995. ISSN 0964-1998.

Brasil. I Plano Nacional de Pós-Graduação. Decreto 76.056, de 30 de julho de 1975. CULTURA, M. D. E. E. Brasilia 1975.

Breen, R.; Goldthorpe, J. H. Explaining educational differentials: Towards a formal rational action theory. Rationality and society, v. 9, n. 3, p. 275-305, 1997. ISSN 1043-4631.

Breneman, D. W. The Ph.D. Production Process. In: BRENEMAN, D. W.;JAMISON, D. T., et al (Ed.). Education as an Industry: NBER, 1976. cap. 1, p.1-52.

CAPES. Discentes da Pós-Graduação Stricto Sensu do Brasil (base de dados confidencial). CAPES. Brasilia 2017a.

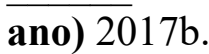

GEOCAPES - Distribuição de Discentes de Pós-graduação no Brasil por Estado (ao final do Tabela de Áreas de Conhecimento/Avaliação. CAPES. Brasilia 2017c.

. GEOCAPES - Distribuição de Programas de Pós-graduação no Brasil por Estado. CAPES. Brasilia 2018.

Coleta de Dados, Discentes dos Programas de Pós-Graduação stricto sensu no Brasil 2004 a 2012. CAPES. Brasilia: CAPES. 20192019. 
Casado, L. J. D.; Migon, H.; Cuminato, J. A. Documento de Área: Matemática, Probabilidade e Estatística. CAPES. Brasilia 2016.

Cohen, K. E. What about Master's Students? The Master's Student Persistence Model. Online Submission, 2012.

Cole, D.; Espinoza, A. The postbaccalaureate goals of college women in STEM. New Directions for Institutional Research, v. 2011, n. 152, p. 51-58, 2011. ISSN 1536-075X.

Colombo, D. G. A Desigualdade no Acesso à Pós-Graduação Stricto Sensu Brasileira: análise do perfil dos ingressantes de cursos de mestrado e doutorado. In: BOF, A. M. e OLIVEIRA, A. S. (Ed.). Cadernos de Estudos e Pesquisas Educacionais. Brasilia: INEP, 2018. p.241-274. ISBN 978-85-7863-065-2.

Council of Graduate Schools. Ph. D. completion and attrition: Policy, numbers, leadership, and next steps: Author Washington, DC 2004.

Davidson, C.; Wilson, K. Reassessing Tinto's concepts of social and academic integration in student retention. Journal of College Student Retention: Research, Theory \& Practice, v. 15, n. 3, p. 329-346, 2013. ISSN 1521-0251.

Durkheim, É. O suicídio: estudo de sociologia. São Paulo: Martins Fontes, 2000. ISBN 85-336-1105-6.

Ehrenberg, R. G.; Mavros, P. G. Do doctoral students' financial support patterns affect their times-todegree and completion probabilities. National Bureau of Economic Research. 1992

Espenshade, T. J.; Rodriguez, G. Completing the Ph. D.: Comparative performances of US and foreign students. Social Science Quarterly, p. 593-605, 1997. ISSN 0038-4941.

Fernandes, E. F. et al. Panorama do Fenômeno da Evasão Discente na Pós-Graduação: uma análise a partir do GEOCAPES. XVII Colóquio Internacional de Gestão Universitária. Mar del Plata - Argentina 2017.

Figueiredo, V. B. d.; Marques, E. d. R.; Birchal, T. d. S. Documento de Área: Filosofia. CAPES. Brasilia 2016.

Frasier, H. S. An analysis of institutional characteristics that contribute to extended time to doctoral degree. 2013.

Geven, K.; Skopek, J.; Triventi, M. How to increase PhD completion rates? An impact evaluation of two reforms in a selective graduate school, 1976-2012. Research in higher education, v. 59, n. 5, p. 529-552, 2018. ISSN 0361-0365.

Girves, J. E.; Wemmerus, V. Developing models of graduate student degree progress. The Journal of Higher Education, v. 59, n. 2, p. 163-189, 1988. ISSN 0022-1546.

Greene, M. Come hell or high water: Doctoral students' perceptions on support services and persistence. International Journal of Doctoral Studies, v. 10, n. 1, p. 501-518, 2015.

Groenvynck, H.; Vandevelde, K.; Van Rossem, R. The PhD track: who succeeds, who drops out? Research Evaluation, v. 22, n. 4, p. 199-209, 2013. ISSN 1471-5449. 
Gururaj, S.; Heilig, J. V.; Somers, P. Graduate student persistence: Evidence from three decades. Journal of Student Financial Aid, v. 40, n. 1, p. 3, 2010. ISSN 0884-9153.

Hagedorn, L. Graduate retention: An investigation of factors relating to older female graduate students (Report No. HE026861). East Lansing, Michigan: National Center for Research on Higher Education.(ERIC Document Reproduction Service No. ED365181), 1993.

Herzig, A. H. Becoming mathematicians: Women and students of color choosing and leaving doctoral mathematics. Review of Educational Research, v. 74, n. 2, p. 171-214, 2004. ISSN 0034-6543.

Hora, D. d.; Jorge, S. R.; Morais, M. M. d. Documento de Área: Letras e Linguística. CAPES. Brasilia 2016.

Jiranek, V. Potential predictors of timely completion among dissertation research students at an Australian faculty of sciences. International Journal of Doctoral Studies, v. 5, n. 1, p. 1-13, 2010.

Kyvik, S.; Olsen, T. B. Increasing completion rates in Norwegian doctoral training: multiple causes for efficiency improvements. Studies in Higher Education, v. 39, n. 9, p. 1668-1682, 2014/10/21 2014. ISSN 0307-5079. Disponível em: < https://doi.org/10.1080/03075079.2013.801427>.

Lovitts, B. E. Leaving the ivory tower: The causes and consequences of departure from doctoral study. Rowman \& Littlefield Publishers, 2002. ISBN 0585383642.

Mastekaasa, A. Educational transitions at graduate level: Social origins and enrolment in PhD programmes in Norway. Acta sociologica, v. 49, n. 4, p. 437-453, 2006. ISSN 0001-6993.

Matute, M. M. The duration of the $\mathrm{PhD}$ at Spain from a stochastic frontier perspective: Is it really a trickor-treat issue? Investigaciones de Economía de la Educación volume 9, v. 9, p. 545-565, 2014.

Mendoza, P.; Villarreal, P.; Gunderson, A. Within-year retention among Ph. D. students: The effect of debt, assistantships, and fellowships. Research in Higher Education, v. 55, n. 7, p. 650-685, 2014. ISSN 03610365.

Mwenda, M. N. Underrepresented minority students in STEM doctoral programs: The role of financial support and relationships with faculty and peers. 2010.

Nerad, M.; Evans, B. Globalization and Its Impacts on the Quality of PhD Education: Forces and Forms in Doctoral Education Worldwide. SensePublishers, 2014. ISBN 9789462095694. Disponível em: $<$ https://books.google.com.br/books?id=fbP0AwAAQBAJ $>$.

OECD. Main Science and Technology Indicators. MSTI 2016-1 . OECD. Paris 2016a.

OECD Science, Technology and Innovation Outlook 2016. OECD Publishing, $2016 b$.

Disponível em: $</$ content/book/sti_in_outlook-2016-en

http://dx.doi.org/10.1787/sti in outlook-2016-en $>$.

Park, C. War of attrition: patterns of non-completion amongst postgraduate research students. Higher Education Review-London-, v. 38, n. 1, p. 48-53, 2005. ISSN 0018-1609.

Paulsen, M. B. The economics of human capital and investment in higher education. The finance of higher education: Theory, research, policy, and practice, p. 55-94, 2001. 
Pires, E. C.; Juca, J. F. T.; Gomes, M. M. Documento de Área: Engenharias I. CAPES. Brasilia 2016.

Sheridan, P. M.; Pyke, S. W. Predictors of time to completion of graduate degrees. Canadian Journal of Higher Education, v. 24, n. 2, p. 68-88, 1994. ISSN 0316-1218.

Siegfried, J. J.; Stock, W. A. So you want to earn a Ph. D. in economics?: How long do you think it will take? Journal of Human Resources, p. 364-378, 2001. ISSN 0022-166X.

Soares, C. J.; Bönecker, M. J. S.; Dias, K. R. H. C. Documento de Área: Área 18-Odontologia. CAPES. Brasilia 2016.

Spady, W. G. Dropouts from higher education: An interdisciplinary review and synthesis. Interchange, v. 1, n. 1, p. 64-85, 1970. ISSN 0826-4805.

Spence, M. Signalling, screening and information. In: ROSEN, S. (Ed.). Studies in Labor Markets: Chicago: Chicago University Press, 1979.

Spronken-Smith, R.; Cameron, C.; Quigg, R. Factors contributing to high PhD completion rates: a case study in a research-intensive university in New Zealand. Assessment \& Evaluation in Higher Education, v. 43, n. 1, p. 94-109, 2018. ISSN 0260-2938.

STF. Recurso Extraordinário 597.854. Relator: Min. Edson Fachin. Brasilia 2017.

Sucupira, N. Parecer n 977/65. C.E.SU e MINISTÉRIO DA EDUCAÇÃO. Brasilia 1965.

Tinto, V. Dropout from higher education: A theoretical synthesis of recent research. Review of educational research, v. 45, n. 1, p. 89-125, 1975. ISSN 0034-6543.

Tinto, V. Leaving College: Rethinking the Causes and Cures of Student Attrition. University of Chicago Press, 1993. ISBN 9780226804491. Disponível em: $<$ https://books.google.com.br/books?id=ABERLYDMg8C >.

Tinto, V. Research and practice of student retention: What next? Journal of College Student Retention: Research, Theory \& Practice, v. 8, n. 1, p. 1-19, 2006. ISSN 1521-0251.

UNESCO. International Standard Classification of Education-ISCED 19971997.

Valentine, N. L. Factors Related to Attrition from Doctor of Education Programs in the College of Human Resources and Education at West Virginia University (Nongraduates, Dropouts, Students). 1987. Dissertation Abstracts International, 47(06A), 270,

Van de Schoot, R. et al. What took them so long? Explaining PhD delays among doctoral candidates. PloS one, v. 8, n. 7, p. e68839, 2013. ISSN 1932-6203.

Van Der Haert, M. et al. Are dropout and degree completion in doctoral study significantly dependent on type of financial support and field of research? Studies in higher education, v. 39, n. 10, p. 1885-1909, 2014. ISSN 0307-5079.

Van Ours, J. C.; Ridder, G. Fast track or failure: a study of the graduation and dropout rates of Ph D students in economics. Economics of Education Review, v. 22, n. 2, p. 157-166, 2003. ISSN 0272-7757. 
Visser, M.; Luwel, M.; Moed, H. The attainment of doctoral degrees at Flemish universities: a survival analysis. Higher Education, v. 54, n. 5, p. 741-757, 2007. ISSN 0018-1560.

Wakeling, P.; Kyriacou, C. Widening participation from undergraduate to postgraduate research degrees: A research synthesis. York, UK: Economic and Social Research Council, 2010.

Walker, G. E. et al. The Formation of Scholars: Rethinking Doctoral Education for the Twenty-First Century. Wiley, 2012. ISBN 9781118428610. Disponível em: < https://books.google.com.br/books?id=9j0f0PQubPYC $>$.

Wollast, R. et al. Who Are the Doctoral Students Who Drop Out? Factors Associated with the Rate of Doctoral Degree Completion in Universities. International Journal of Higher Education, v. 7, n. 4, p. 143-156, 2018. ISSN 1927-6044.

Zhou, E.; Okahana, H. The role of department supports on doctoral completion and time-to-degree. Journal of College Student Retention: Research, Theory \& Practice, v. 20, n. 4, p. 511-529, 2019. ISSN 15210251 .

Zwick, R. Differences in Graduate School Attainment Patterns across Academic Programs and Demographic Groups. A Research Report of the Minority Graduate Education Project. 1991. 